\section{Pacific Northwest}

National Laboratory

Operated by Battelle for the

U.S. Department of Energy

\section{Analytical Method for the Detection of Ozone Depleting Chemicals (ODC) in Commercial Products Using a Gas Chromatograph with an Electron Capture Detector (GC-ECD)}

RN Lee

BP Dockendorff

BW Wright

September 2007

Prepared for the Internal Revenue Service under an Interagency Agreement with the U.S. Department of Energy under Contract DE-AC05-76RL01830 


\title{
Analytical Method for the Detection of Ozone Depleting Chemicals (ODC) in Commercial Products Using a Gas Chromatograph with an Electron Capture Detector (GC-ECD)
}

\author{
R. N. Lee \\ B. P. Dockendorff \\ B. W. Wright
}

September 2007

Prepared for the Internal Revenue Service under an Interagency Agreement with the U.S. Department of Energy under Contract DE-AC05-76RL01830

Pacific Northwest National Laboratory

Richland, Washington 99352 



\section{Summary}

This document describes an analytical procedure that was developed for the trace level detection of residual ozone depleting chemicals (ODC) associated with the manufacture of selected commercial products. To ensure the United States meets its obligation under the Montreal Protocol, Congress enacted legislation in 1989 to impose an excise tax on electronic goods imported into the United States that were produced with banned chemicals. This procedure was developed to technically determine if residual ODC chemicals could be detected on electronic circuit boards. The analytical method utilizes a "purge and trap" technique followed by gas chromatography with electron capture detection to capture and analyze the volatile chemicals associated with the matrix. The method describes the procedure, the hardware, operating conditions, calibration, and quality control measures in sufficient detail to allow the capability to be replicated. This document corresponds to internal Standard Operating Procedure (SOP) EFL-130A, Rev 4. 



\section{Glossary}

$\begin{array}{ll}\text { ECD } & \text { electron capture detector } \\ \text { EFL } & \text { Excise Forensics Laboratory } \\ \text { GC } & \text { gas chromatograph } \\ \text { HTST } & \text { high temperature set point method } \\ \text { ID } & \text { inner diameter } \\ \text { IRS } & \text { Internal Revenue Service } \\ \text { LTSP } & \text { low temperature set point method } \\ \text { OD } & \text { outer diameter } \\ \text { ODC } & \text { ozone depleting chemicals } \\ \text { PCB } & \text { printed circuit board } \\ \text { PNNL } & \text { Pacific Northwest National Laboratory } \\ \text { QA } & \text { quality assurance } \\ \text { SOP } & \text { Standard Operating Procedure }\end{array}$





\section{Contents}

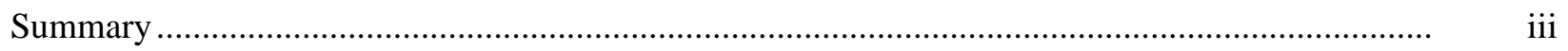

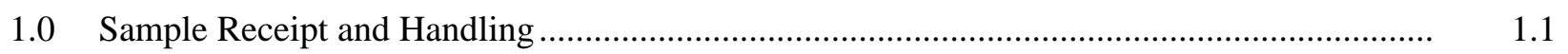

2.0 Method Description............................................................................................

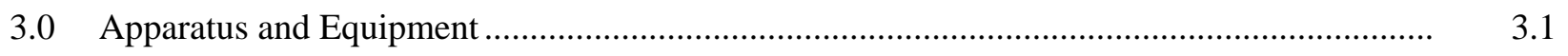

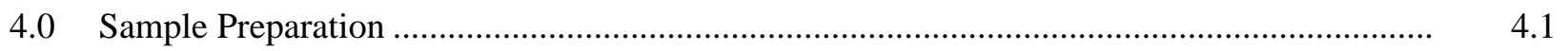

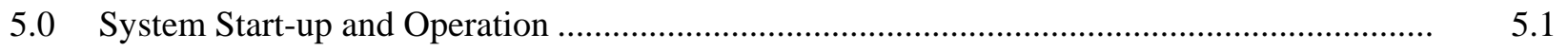

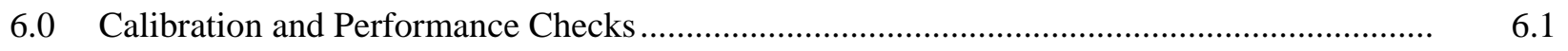

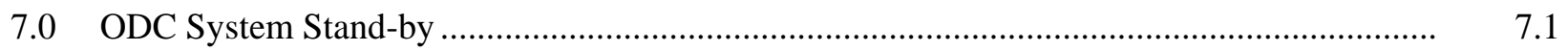

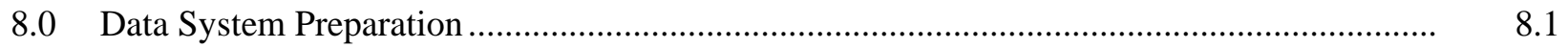

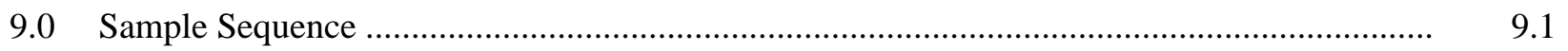

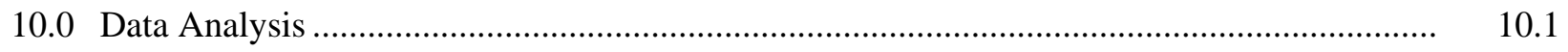

Appendix A ～GC Method Sequence Tables............................................................................ A.1

Appendix B $\quad$ Method A Information .................................................................................. B.

Appendix C $\quad$ Method B Information ….............................................................................. C.1

Appendix D ～ODC-GC Daily Sample Log …............................................................... D.1

Appendix E $\quad$ Excel Spreadsheet - Data Form with Functions Displayed................................... E. $\quad$ E 


\section{Figures}

3.1. Schematic of the ODC Gas Chromatographic System with Valves Directing Purge and Carries Gas Flows

4.1. Photograph of a Sealed Tedlar Bag with a Circuit Board Enclosed

5.1. Computer Display of Overlaid Chromatograms for Purge Gas Samples Collected with a Circuit Board Sample at $\sim 23^{\circ} \mathrm{C}$ (blue trace) and $35^{\circ} \mathrm{C}$ (red trace) for Analysis B.

5.2. Plot of the Relative Peak Areas Versus Purge Gas Sample Number for a Home Electronics Circuit Board.

6.1. Diagram Illustrating the Double-Enclosed Permeation Source Containing ODC Standards

6.2. Sample Chamber Showing Tedlar Bag Used for Injecting Standards.

6.3. Chromatograms of Purge Gas Sample from September 13, 2005, Permeation Source Using Analysis Methods A (top) and B (bottom)....

10.1. Overlaid Chromatograms Demonstrating the Effect of Temperature on Analyte Peak Areas with a Circuit Board Sample at Room Temperature (blue trace) and $35^{\circ} \mathrm{C}$ (red trace).

\section{Tables}

4.1. Sample Preparation Steps

5.1. GC Operating Parameters for Analysis A (ODC-GC1) and Analysis B (ODC-GC2)

6.1. Volatile Halocarbon Standards.

6.2. Purge Gas and System Blanks

6.3. Halocarbon Composition of September 13, 2005, Permeation Source

9.1. Injection Sequence for Residual ODC Detection in Circuit Board Sample

9.2. Analysis Sequence for a Set of Five Circuit Boards (1 QA and 4 new samples)

9.3. Taxable Ozone Depleting Chemicals 


\subsection{Sample Receipt and Handling}

All commercial products to be analyzed for residual ozone depleting chemicals (ODC) are received under chain-of-custody control. For samples (products) received from off-site locations, written and signed receipts using chain-of-custody documentation are required using established procedures. This requires that such samples were properly collected and documented for shipment. Samples collected by Excise Forensics Laboratory (EFL) personnel are purchased at retail outlets and personally held in their custody until secured within the EFL. The EFL is a secure facility with access limited to properly trained and cleared Pacific Northwest National Laboratory (PNNL) staff. Sample receipt documentation (i.e., item description, purchase date, purchase location, EFL staff signature and date, and copies of sales receipts) is prepared acknowledging receipt and inspection (intact and sealed packages) of the product at the EFL. Samples include consumer products that were potentially produced using ODCs that are regulated under Internal Revenue Service (IRS) regulations. Typical examples include electronic circuit boards from electronic products, various types of foams, etc. This protocol specifically applies to electronic circuit boards, but is also applicable to any other imported consumer product of interest.

Each sample is logged into the EFL Research Sample Database. Information included with the sample entry includes receipt date, sample description, serial number, the computer-assigned EFL barcode number, and any other descriptive information that allows the specific product to be uniquely identified. After the sample is logged into the database, the barcode number is printed in quadruplicate on label tape. One barcode is applied to the sample-packaging box (if it arrived in its original packaging). The box is then opened and labels are attached to the individual components of interest contained within the box. The serial number(s) on the component(s) are verified to those on the outside packaging (box).

All components are then returned to the box and secured in a locked storage cabinet until ready for further processing. For a circuit board sample that is received in a bag, the barcode is applied to the bag and the bag is securely closed to ensure the board and bag remain associated with each other. 



\subsection{Method Description}

This method was developed for identifying residual ODCs in selected commercial products using gas chromatography with electron capture detection. Screening analysis is done with one type of column followed by conformational analysis using the same, or similarly configured, gas chromatograph, equipped with an orthogonal column to positively identify residual solvents.

This capability is an adaptation of various EPA (SW846) "purge-and-trap" methods that are established analytical techniques for the detection of volatile organics. Purge gas samples are obtained by flushing a container (Tedlar bag) holding a printed circuit board, or other solid matrix, with high-purity helium. The volatile species that are thermally released from the sample are collected by passing the purge gas effluent through a liquid nitrogen-cooled collection trap. The Tedlar bag is housed in a temperature-controlled oven. Initial purge gas samples are collected with the test material at room temperature $\left(\sim 23^{\circ} \mathrm{C}\right)$ before warming the sample chamber to $40^{\circ} \mathrm{C}$ for subsequent sample collection and analysis. Trapped analytes are released by heating the trap and are transported with helium carrier gas to a gas chromatograph (GC) column where they are efficiently retained at the front of the column. Collection and release of analytes is automated with a six-port gas-sampling valve and cryogenic trap. Following transfer, with the column oven at a fixed temperature, a two-step temperature program is initiated to transport collected analytes through the column to an electron capture detector (ECD). Two independent GC analysis methods are performed for each sequence of purge gas samples. One method is used to tentatively identify ODC solvents based on retention time matches to external calibration standards. The second method uses a separate chromatographic column with different selectivity to confirm the initial peak identifications. Method A uses a PoraBOND Q (bonded porous polymer) column while method B uses a Quadrex 624 (cyanopropylphenyl methylpolysiloxane) thick-film column.

In practice, two identically configured instruments (except for the column) are used, but by changing the column back and forth, a single instrument could be used. Before circuit board analysis, a blank analysis is performed with an empty Tedlar bag to demonstrate the absence of trace contaminants. Circuit board characterization is achieved through an analysis sequence consisting of four or more purge gas samples. Initial purge gas samples, collected with the circuit board at room temperature $\left(\sim 23^{\circ} \mathrm{C}\right)$, are analyzed two times to establish a uniform, baseline signal for the helium purge gas sample. At least two subsequent purge gas samples, obtained with the sample chamber at $40^{\circ} \mathrm{C}$, are used to identify materials released from the circuit board matrix. Volatile solvents introduced to the matrix during circuit board production are slowly released over time. Accelerated release of solvents from the solid matrix at higher temperatures and the consequent increase in their associated peak areas are used to identify residual solvents in the circuit board matrix. Data interpretation is based on relative peak area increase obtained upon heating the circuit board rather than quantitative measurement of solvent residues at any given temperature. 



\subsection{Apparatus and Equipment}

A schematic of the system is shown in Figure 3.1 and the specific components are identified in the following paragraphs.

3.1 The primary component of this system consists of a commercial gas chromatograph (Agilent 6890) equipped with a heated automated gas-sampling valve (Valco six-port valve, part number D6UWE) and a micro electron capture detector. The GC is equipped with three auxiliary channels of electronic pressure/flow control modules for the carrier gas, the helium purge gas, and the detector make-up gas. The GC oven is also equipped with cryogenic cooling. The ECD and valve vent line are vented to the building ventilation system to minimize contamination of the ambient laboratory air.

3.2 An automated cryogenic trap collects analytes and releases them to the GC column (Scientific Instrument Services, Inc. GC Cryo-Trap, Model 961). The GC controls the cryogenic trap. The cryotrap itself is a $6.7 \mathrm{in.} \times 0.125$ in. outer diameter (OD) $\times 2.6 \mathrm{~mm}$ inner diameter (ID) 304 stainless steel tube packed with $70 \mathrm{mg}$ of silylated glass wool.

3.3 A Quincy Lab, Inc. Model 12-140AE incubator oven is used as the sample chamber for heating circuit boards for desorption. The oven was modified to allow temperature set points to be controlled by the GC through valve commands to an Omega CN77R333RSP temperature controller.

3.4 Upstream components of the analytical system include a helium gas scrubber (Varian Gas Clean GC/MS Filter, product number CP17973, with connection unit CP7965) and a two-position valve (VICI 4-port valve, product number 4UWE, with microelectric actuator) to direct the helium purge gas through the sample container (purge) or to vent (bypass).

3.5 Pre-cleaned Tedlar sample bags (verified to be ODC free) with Swagelok stainless steel fittings (Jensen Inert Products) were used in various dimensions to accommodate the range of circuit board sizes. Each bag is tagged with a unique identification number and conditioned before use.

3.6 A soap film bubble meter (Hewlett Packard 0101-0113) was used to measure gas flows.

3.7 The data system was a Dell Precision 330 or Dell Latitude Laptop with Agilent GC ChemStation software, version Rev. A 10.2.

3.8 Liquid nitrogen was stored and dispensed from Dewar flasks (35 liter, Taylor-Wharton 35LD or equivalent, with liquid nitrogen withdrawal device).

3.9 Capillary GC column A was a Varian CP-PoraBOND Q-fused silica, 25 m, 250 micron ID, 3 micron film thickness, product number CP7348 or Varian CP-PoraBOND Q fused silica, 25 m, 320 micron ID, 3 micron film thickness, product number CP7351.

3.10 Capillary GC column B was a Restek Rtx-624 fused silica, 30 m, 320 micron ID., 1.8 micron film thickness, catalog number 10970. 


\section{Purge Gas Sample Chamber Valve}

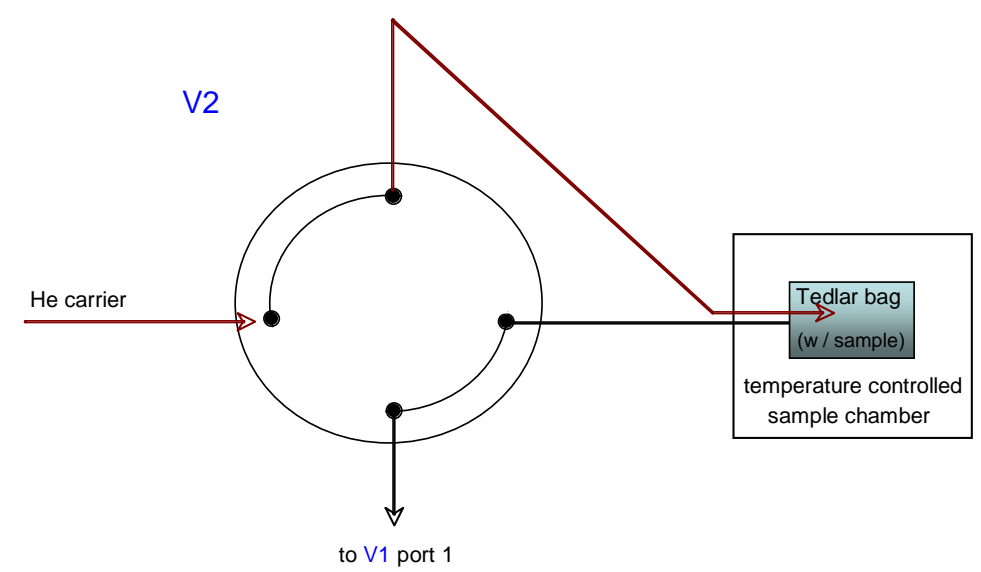

Sample Concentration / Collection
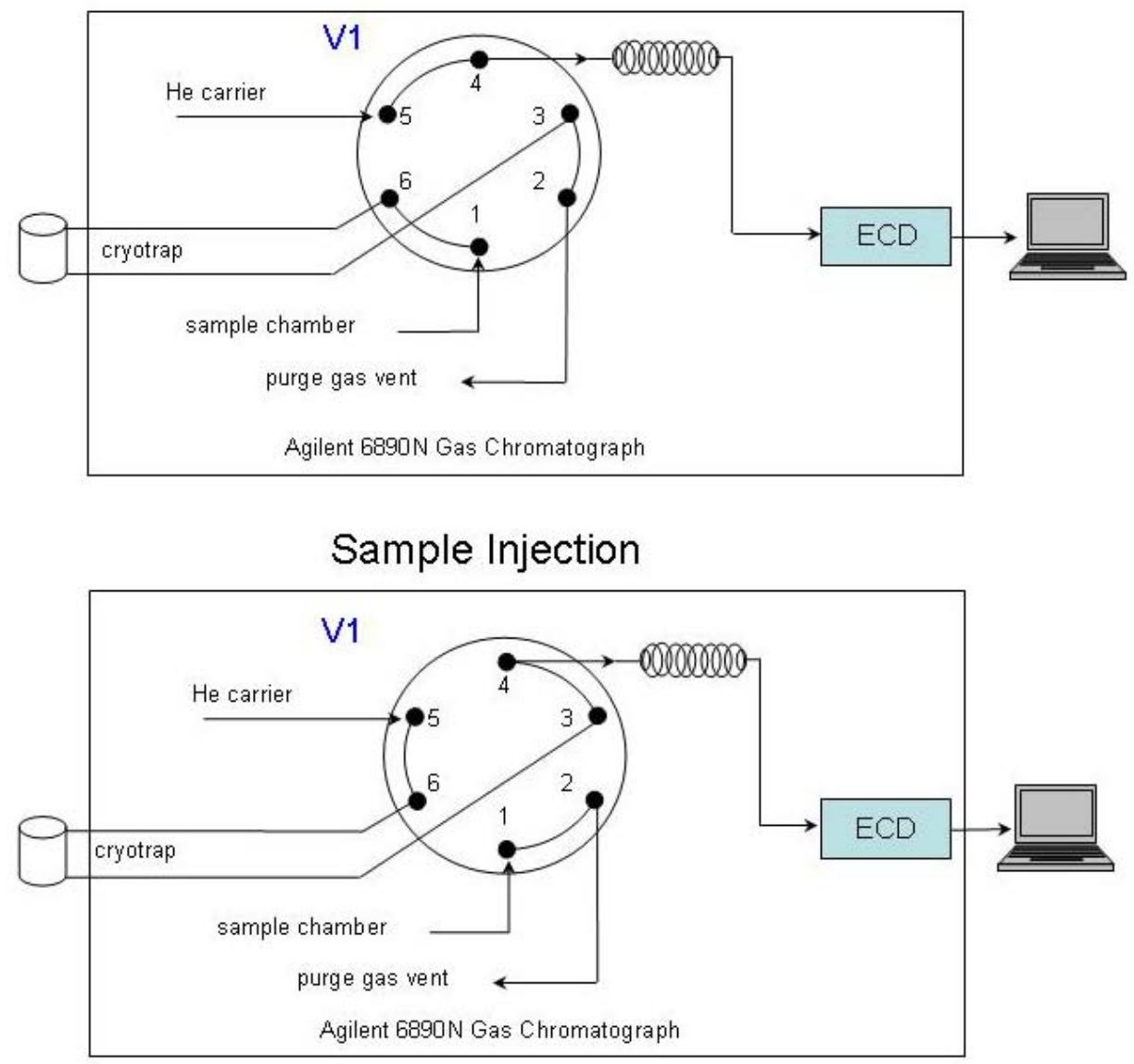

Figure 3.1. Schematic of the ODC Gas Chromatographic System with Valves Directing Purge and Carries Gas Flows. GC ChemStation controls operation of valves. 


\subsection{Sample Preparation}

The following section describes the procedure to be followed for removing printed circuit boards (PCBs) from electronic products, their insertion into Tedlar bags, and subsequent transfer to the purge gas system for analysis. Each step in the process, identified in Table 4.1, is photographed to provide a visual record to track the material (product and laboratory identification numbers) under examination and provide back-up information to support circuit board analysis records and associated data files. Items are laid out and photographed to ensure that the boards, bags, devices, etc. can be visually identified and associated. The photograph files for each sample are stored in a folder dedicated to that sample on the secure laboratory data server.

Table 4.1. Sample Preparation Steps

\begin{tabular}{|c|l|c|}
\hline Step & \multicolumn{1}{c|}{ Description } \\
\hline 1 & $\begin{array}{l}\text { The box containing the product of interest is removed from the storage cabinet and the } \\
\text { enclosed product removed. The sticker with the lab identification number previously } \\
\text { affixed to the outside of the product is compared to the sticker on the packaging box to } \\
\text { ensure they are the same. A clean work surface is prepared by placing a new paper towel } \\
\text { (Kimwipes EX-L) over the table used for sample preparation. New laboratory gloves } \\
\text { (cotton inspection gloves) are also used with each circuit board sample to prevent } \\
\text { inadvertent transfer of contaminants between samples. }\end{array}$ \\
\hline 2 & $\begin{array}{l}\text { The product is opened to gain access to the PCB or boards. This process generally requires } \\
\text { the removal of a few easily accessible screws. Remove the screws holding the PCB in } \\
\text { place and cut wires to allow the PCB to be separated from the housing. Where the product, } \\
\text { or component, contains more than one PCB, one is removed for analysis and the remaining } \\
\text { board(s) are returned to storage with the product or component housing. }\end{array}$ \\
\hline 3 & $\begin{array}{l}\text { The PCB is removed, transferred to a Tedlar bag, and the bag sealed by folding the open } \\
\text { end of the bag over itself and sandwiching the fold between two aluminum bars as shown } \\
\text { in Figure 4.1. Sealing the Tedlar bag clamp requires an opened ended wrench (5/16 in.) } \\
\text { and an Allen wrench. All Tedlar bags are assigned a unique number to permit tracking. } \\
\text { Before use, they are conditioned with purge gas flow at elevated temperature, and then } \\
\text { subjected to purge gas tests to verify the absence of contamination. }\end{array}$ \\
\hline 4 & $\begin{array}{l}\text { The identification number of the bag is recorded on the "ODC Daily Sample Log” and the } \\
\text { bag is installed in the sample chamber with gas flow set to the "purge" position to flush } \\
\text { ambient air from the bag. }\end{array}$ \\
\hline
\end{tabular}




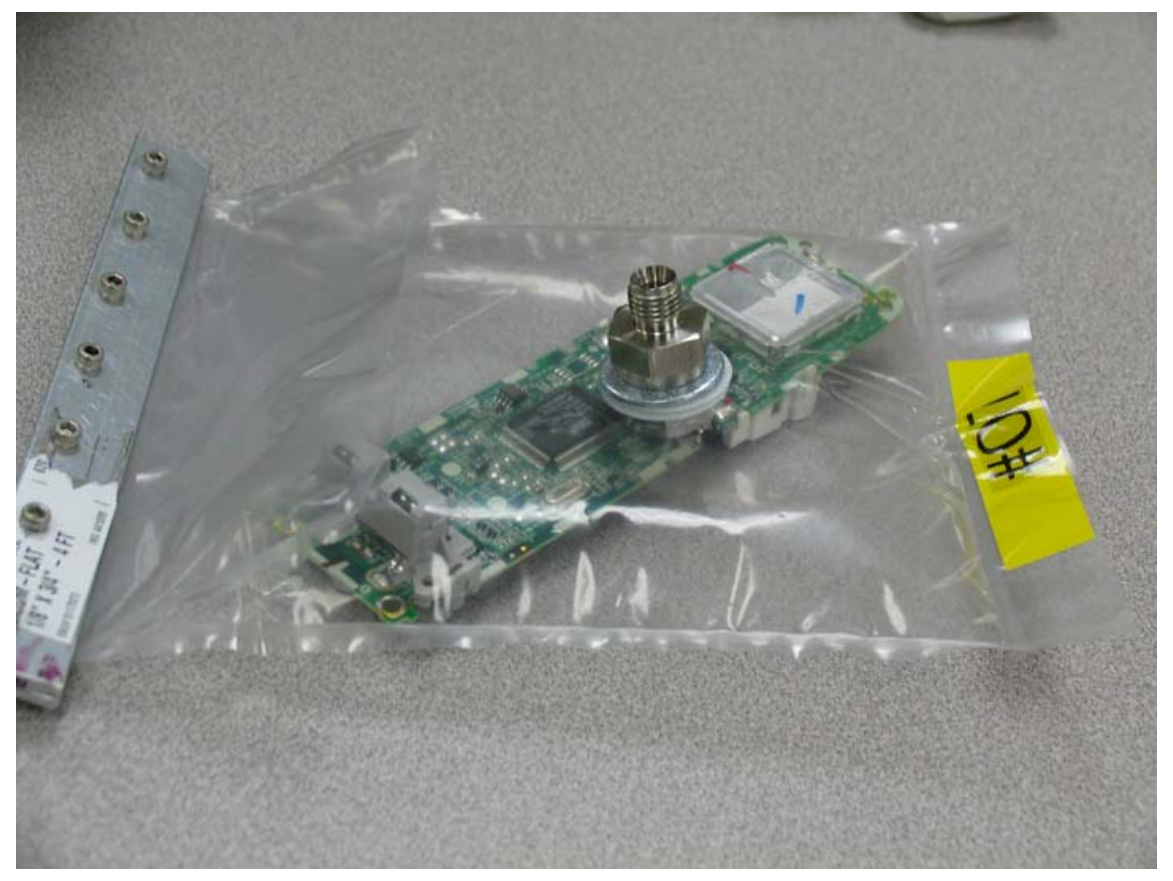

Figure 4.1. Photograph of a Sealed Tedlar Bag with a Circuit Board Enclosed 


\subsection{System Start-up and Operation}

5.1 Operation can be performed in a fully automated or partially automated mode. Under full automation, a ChemStation sequence table (see Appendix A) controls several GC methods that perform all the necessary functions for the analyses of the two purge gas samples collected at room temperature and for the two elevated temperature purge gas samples. There are three different methods that are used to perform an automated sample analysis. The main method (Method A or B, depending on the specific column being used) controls the sampling valves, the cryotrap, and the GC. The sub methods are identical except that they also control the temperature in the sample chamber. Method A HTST, or the high temperature set point control method, increases the temperature in the sample chamber to $40^{\circ} \mathrm{C}$ after the sampling period of the current run has finished. Conversely, Method A LTSP, the low temperature set point method, lowers the sample chamber temperature to room temperature after the sampling period of the current run has completed. This method scheme is the same for Method B in which there is also a B HTST and B LTSP. In the partially automated mode, each purge gas sample analysis is manually started, but the individual GC method, including the cryotrap and sample valve, is fully automated. To simplify method description, the partially automated mode is primarily described.

5.2 Two chromatographic systems are used for product analysis, ODC-GC1 for analysis Method A and ODC-GC2 for analysis Method B. One method is used to screen for ODCs and if their presence is indicated, the second method is used to confirm the identification of ODC solvents. (Either method can be used as the screening method.) Methods for the respective analytical tasks are stored on the ChemStation computer and the methods are also saved with all electronic data files on the laboratory server. The gas chromatograph is under computer control when connected through the LAN cable and ChemStation software is booted (INSTRUMENT 1 or 2 ON-LINE). GC parameters associated with each of the automated methods (defined as A.M and B.M by the ChemStation) are summarized in Table 5.1, and a full printout of these methods is found in Appendices B and C, respectively.

5.3 The column oven is heated at $150^{\circ} \mathrm{C}$ for at least 30 minutes before initiating the first analysis of the day. Whenever analysis is delayed while newly installed Tedlar sample bags are being purged for removal of ambient air, the oven is reset to $150^{\circ} \mathrm{C}$. When purge gas analysis is resumed, the column oven temperature is reset by loading the appropriate method (A.M or B.M) in preparation for sample analysis. System conditions are set by the method and verified as recorded in Table 5.1 before starting the analysis of purge gas samples from the newly installed Tedlar bag.

5.4 Data reduction to identify residual solvents from the circuit board matrix is based on the calculation of volume normalized peak areas. Purge gas flow is controlled and held constant with the GC electronic pressure/flow control and the sample time is likewise controlled by the GC automation. From validation studies using $500 \mathrm{~mL}$ Tedlar bags, a collection period of 10 minutes (200 mL purge gas volume) has been found to provide adequate sample, if residue solvents are present. 
Table 5.1. GC Operating Parameters for Analysis A (ODC-GC1) and Analysis B (ODC-GC2)

\begin{tabular}{|c|c|c|c|}
\hline \multicolumn{4}{|c|}{ Method A.M. } \\
\hline Initial Temperature 1 & $30^{\circ} \mathrm{C}$ & Sample valve temperature & $100^{\circ} \mathrm{C}$ \\
\hline Initial Time & 16.0 minutes & Constant flow carrier gas & $1.8 \mathrm{~mL} / \mathrm{min}$ \\
\hline Rate 1 & $100^{\circ} \mathrm{C} / \mathrm{min}$ & Purge gas pressure & $20 \mathrm{psi}$ \\
\hline Final Temperature 2 & $80^{\circ} \mathrm{C}$ & & \\
\hline Time & 0.0 minutes & Helium carrier initial pressure & $16.0 \mathrm{psi}$ \\
\hline Rate 2 & $8^{\circ} \mathrm{C} / \mathrm{min}$ & & \\
\hline Final Temperature 3 & $216^{\circ} \mathrm{C}$ & Column: Varian CP7348, Porabond Q & \\
\hline Time & 5.0 minutes & 25 m, 250 micron ID, 3.0 micron film & \\
\hline Total analysis time & 38.5 minutes & & \\
\hline \multicolumn{4}{|c|}{ Method B.M. } \\
\hline Initial Temperature 1 & $-20^{\circ} \mathrm{C}$ & Sample valve temperature & $100^{\circ} \mathrm{C}$ \\
\hline Initial Time & 16.0 minutes & Constant flow carrier & $1.5 \mathrm{~mL} / \mathrm{min}$ \\
\hline Rate 1 & $100^{\circ} \mathrm{C} / \mathrm{min}$ & Purge gas pressure & $20 \mathrm{psi}$ \\
\hline Final Temperature 2 & $30^{\circ} \mathrm{C}$ & & \\
\hline Time & 0.0 minutes & Helium carrier initial pressure & 8 psi \\
\hline Rate 2 & $10^{\circ} \mathrm{C} / \mathrm{min}$ & & \\
\hline Final Temperature 3 & $200^{\circ} \mathrm{C}$ & Column: Restek Rtx-624 & \\
\hline Time & 4.0 minutes & 30 m, 320 micron ID, 1.8 micron film & \\
\hline Total analysis time & 37.7 minutes & & \\
\hline
\end{tabular}

5.5 System automation controls sampling and analysis of the purge gas samples collected from the Tedlar bag. After a bag has been connected and purged, the analysis sequence is initiated. Sample information (sample identification, Tedlar bag number) is entered into the ChemStation using the appropriate menu command. The purge gas flow is set to the bypass position, the cryotrap cools to $-190^{\circ} \mathrm{C}$ and, after stabilizing for 3 minutes, the purge flow switches to the purge mode and the gas sample is collected for 10 minutes. The cryotrap then heats to $100^{\circ} \mathrm{C}$, the sample valve (Valve 1 ) switches to the "inject" position, and after 3 minutes the GC temperature program starts. When the GC temperature program starts, the sample valve returns to the "load" position. Although no operator intervention is required, the operator may monitor system conditions during purge gas sample collection and verify parameters relevant to data interpretation (zone temperatures, purge and carrier flows $^{\text {(a) }}$, and sample injection time). After initial installation of the Tedlar bag and prior to initiating the analysis sequence, the purge gas flow rate should be monitored to ensure the bag is not leaking.

5.6 Post-analysis responsibilities of the operator include documenting and organizing analysis information. Hand-written notes (ODC-GC Daily Sample Log, see Appendix D) are then signed and dated by the operator and stored in the instrument log file folder maintained with the ODC system. The Agilent ChemStation Data System records the detector signal and assigns a unique, date-encoded

(a) A gas flow bubble meter is used to continuously monitor He purge gas flow. This meter is positioned at the purge gas vent, downstream of the cryogenic trap. 
sequential file name to each chromatogram. Hand-recorded operator notes are taken to record the sample identification, the identification number of the Tedlar bag, chromatographic file names, temperature of the sample chamber, and any other relevant information. While the electronic files created by the instrument contain all the necessary documentation, the notes and logs provide independent verification of sample identity and analysis conditions.

5.7 After each series of analyses corresponding to a given circuit board, the operator prepares a preliminary report to identify residual solvents associated with that board. These results are based on the relative magnitude of the respective chromatographic peaks for circuit board samples at room temperature and $40^{\circ} \mathrm{C}$. The validity of these results rests on the established uniform run-to-run sample volumes (consistent purge gas flow and sampling times). An example of overlaid chromatograms is illustrated in Figure 5.1.

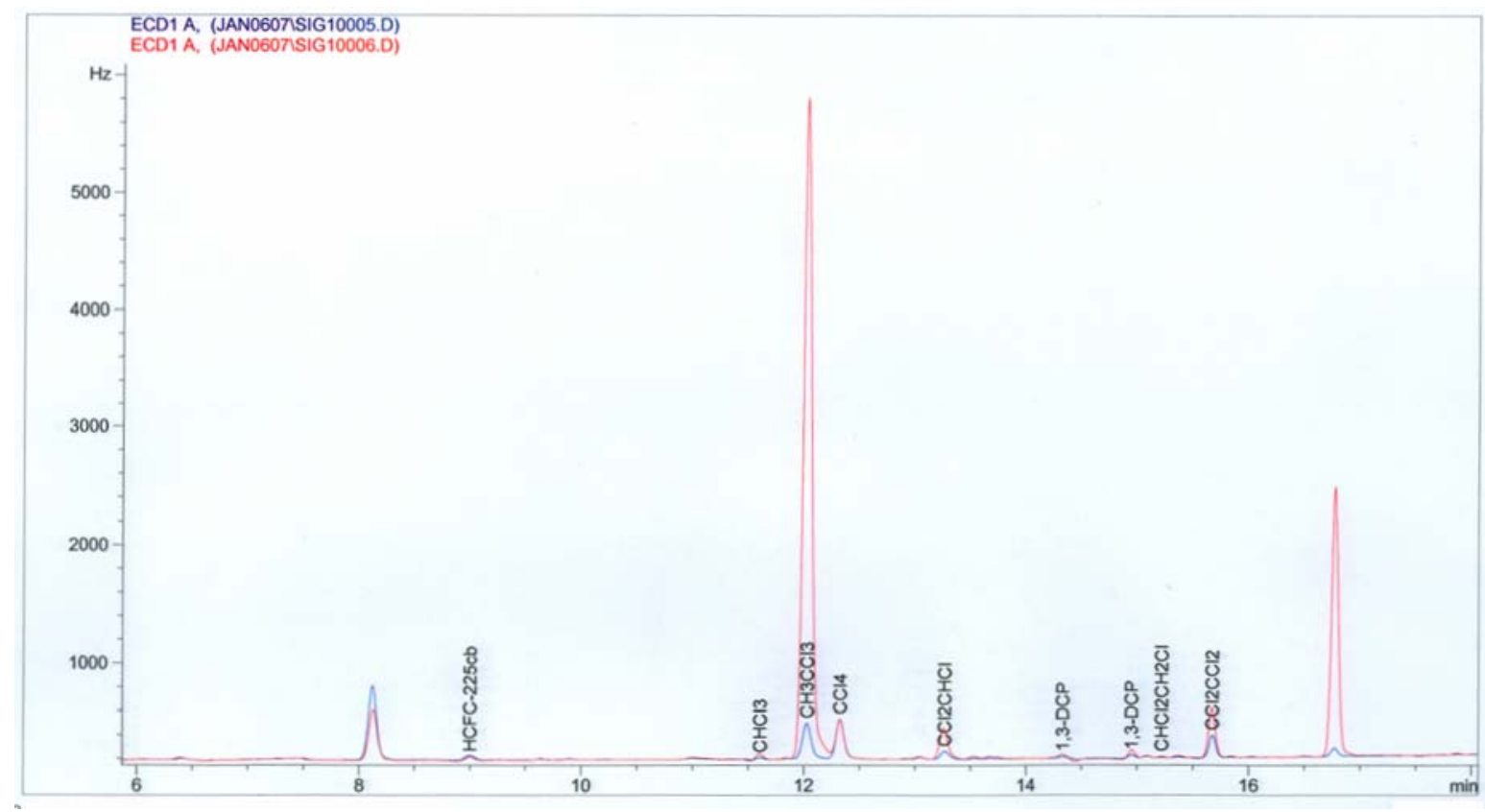

Figure 5.1. Computer Display of Overlaid Chromatograms for Purge Gas Samples Collected with a Circuit Board Sample at $\sim 23^{\circ} \mathrm{C}$ (blue trace) and $35^{\circ} \mathrm{C}$ (red trace) for Analysis B.

5.8 Final determination of analytes associated with a given circuit board is achieved by recording volume normalized peak areas in an Excel spreadsheet. The volume normalized peak areas for each analyte detected in purge gas samples is calculated based on the raw area counts and the computer-controlled sample collection times and purge gas flow rates. The data entry portion of the Excel spreadsheet is shown in Appendix E. In the fully automated mode, the ChemStation exports the peak areas for analytes of interest to Excel for processing and plotting. The spreadsheet tabulates peak areas for each analyte observed in chromatograms corresponding to the sample at $40^{\circ} \mathrm{C}$ relative to those under baseline (room temperature) conditions. Plots of the relative peak areas of all analytes versus purge gas sample number are prepared from these data and provide a simple graphical presentation of the effect of sample temperature on ODC peak areas. An example plot from a series of purge gas 
samples from a home electronics circuit board is shown in Figure 5.2. Chemicals that display three times greater relative peak areas at the elevated temperature are considered to be present in the board matrix.

Home Electronics Circuit Board

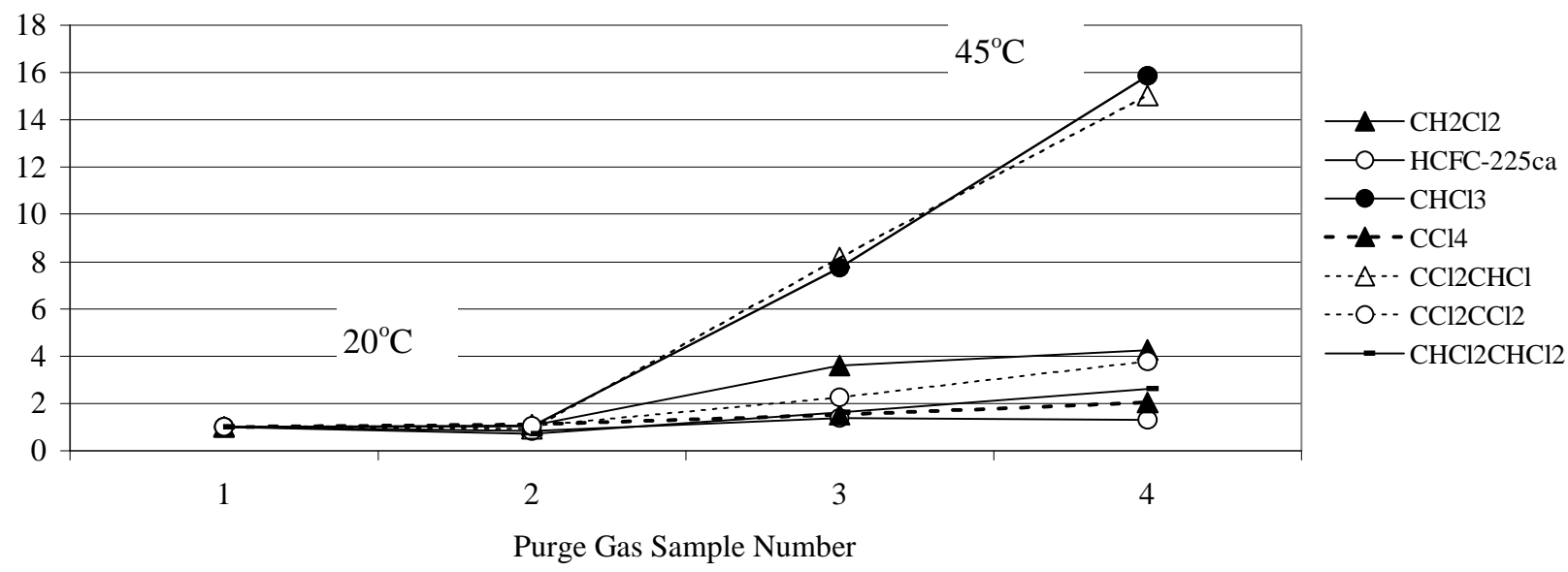

Figure 5.2. Plot of the Relative Peak Areas Versus Purge Gas Sample Number for a Home Electronics Circuit Board 


\subsection{Calibration and Performance Checks}

6.1 Small quantities of ODC chemicals and other volatile halocarbons are used as qualitative standards for periodic analyte retention time calibration checks. Initial calibration is done using individual standards to ensure correct retention time assignment. A calibration table can be established using the ChemStation software, but only compound retention time is relevant. Various analyte mixtures are made as check standards. Volatile halocarbons that are used as standards are listed in Table 6.1. The taxable ODC chemicals are listed later in Table 9.3.

6.2 Vapor standards of the chemicals are prepared as described below. An analyte or analyte mixture is added to a $2 \mathrm{~mL}$ glass GC vial with a Teflon/silicon rubber septum. This vial is then placed into a $6 \mathrm{~mL}$ headspace vial with an aluminum crimp-top seal and butyl rubber septum. The secondary headspace in this vial is then sampled via a gas-tight Hamilton 10- $\mu$ l syringe. Once the sample is taken from the secondary headspace, it is injected through a butyl rubber septum into a $1 \mathrm{~L}$ Tedlar bag for analysis. The amount of standard that is injected can be optimized based upon the detection requirements for that analyte or analyte mixture. The permeation source is stored at $4^{\circ} \mathrm{C}$ in an adjacent laboratory while not in use.

Table 6.1. Volatile Halocarbon Standards

\begin{tabular}{||l|c|c|c||}
\hline \multicolumn{1}{|c|}{ Chemical Name } & Chemical Formula & CAS & Physical State \\
\hline HCFC-141b & $\mathrm{C}_{2} \mathrm{H}_{3} \mathrm{Cl}_{2} \mathrm{~F}$ & {$[1717-00-6]$} & liquid \\
\hline HCFC-225ca & $\mathrm{C}_{3} \mathrm{HCl}_{2} \mathrm{~F}_{5}$ & {$[422-56-0]$} & liquid \\
\hline HCFC-225cb & $\mathrm{C}_{3} \mathrm{HCl}_{2} \mathrm{~F}_{5}$ & {$[507-55-1]$} & liquid \\
\hline HFC-4310m & $\mathrm{C}_{5} \mathrm{H}_{2} \mathrm{~F}_{10}$ & {$[138495-42-8]$} & liquid \\
\hline HFE-7100 & $\mathrm{C}_{5} \mathrm{H}_{3} \mathrm{~F}_{9} \mathrm{O}$ & {$[163702-08-7]$} & liquid \\
\hline HFE-7200 & $\mathrm{C}_{4} \mathrm{~F}_{9} \mathrm{OC}_{2} \mathrm{H}_{5}$ & {$[163702-05-4]$} & liquid \\
\hline 2-bromopropane & $\mathrm{C}_{3} \mathrm{H}_{7} \mathrm{Br}_{2}$ & {$[75-26-3]$} & liquid \\
\hline 1,1,2-trichloroethane & $\mathrm{C}_{2} \mathrm{H}_{3} \mathrm{Cl}_{3}$ & {$[79-00-5]$} & liquid \\
\hline 1,1,2-trichloroethylene & $\mathrm{C}_{2} \mathrm{HCl}_{3}$ & {$[79-01-6]$} & liquid \\
\hline 1,1,2,2-tetrachloroethane & $\mathrm{C}_{2} \mathrm{H}_{2} \mathrm{Cl}_{4}$ & {$[79-34-5]$} & liquid \\
\hline 1,1,1,2-tetrachloroethane & $\mathrm{C}_{2} \mathrm{H}_{2} \mathrm{Cl}_{4}$ & {$[630-20-6]$} & liquid \\
\hline 1,1,2,2-tetrachloroethylene & $\mathrm{C}_{2} \mathrm{Cl}_{4}$ & {$[127-18-4]$} & liquid \\
\hline 1,2-dichloroethane & $\mathrm{C}_{2} \mathrm{H}_{4} \mathrm{Cl}_{2}$ & {$[107-06-2]$} & liquid \\
\hline 1,2-dichloroethylene & $\mathrm{C}_{2} \mathrm{H}_{2} \mathrm{Cl}_{2}$ & {$[540-59-0]$} & liquid \\
\hline 1,3-dichloropropene & $\mathrm{C}_{3} \mathrm{H}_{4} \mathrm{Cl}_{2}$ & {$[542-75-6]$} & liquid \\
\hline methylene chloride & $\mathrm{CH}_{2} \mathrm{Cl}_{2}$ & {$[75-09-2]$} & liquid \\
\hline
\end{tabular}




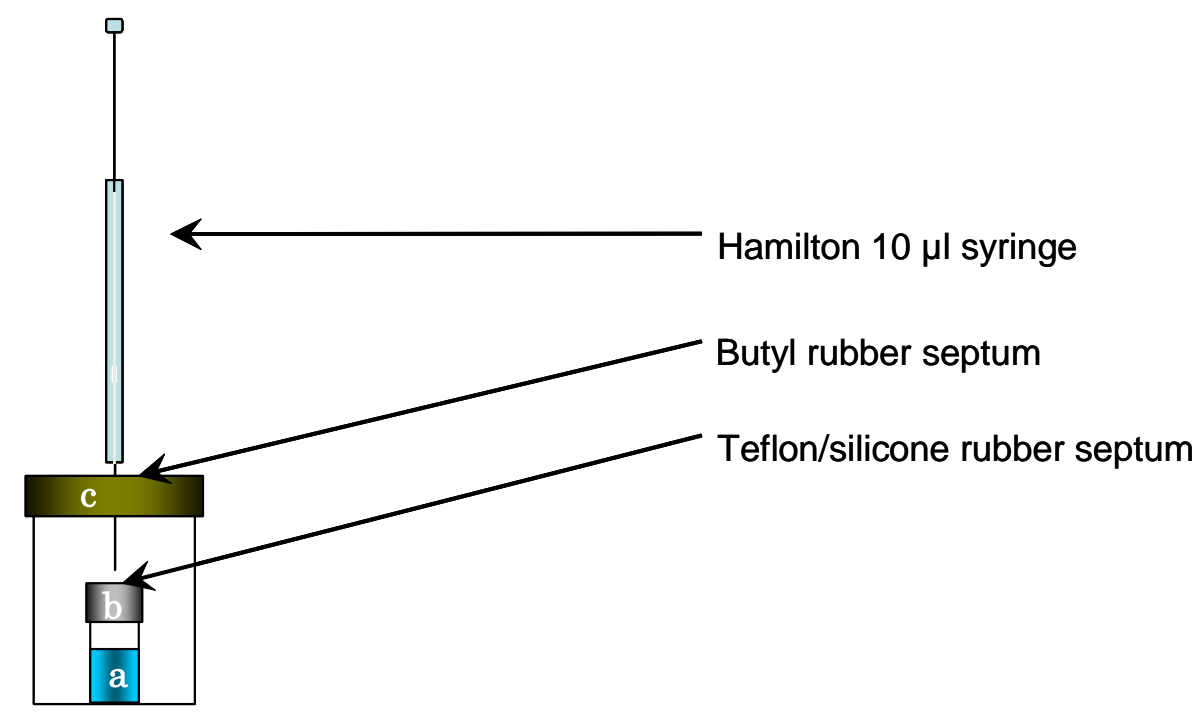

a) Liquid halocarbon standard / mixture

b) GC vial $(2.0 \mathrm{~mL})$

c) $6 \mathrm{~mL}$ headspace vial (38 $\mathrm{mm}$ height $\times 22 \mathrm{~mm}$ diameter) with aluminum crimp-top seal

Figure 6.1. Diagram Illustrating the Double-Enclosed Permeation Source Containing ODC Standards

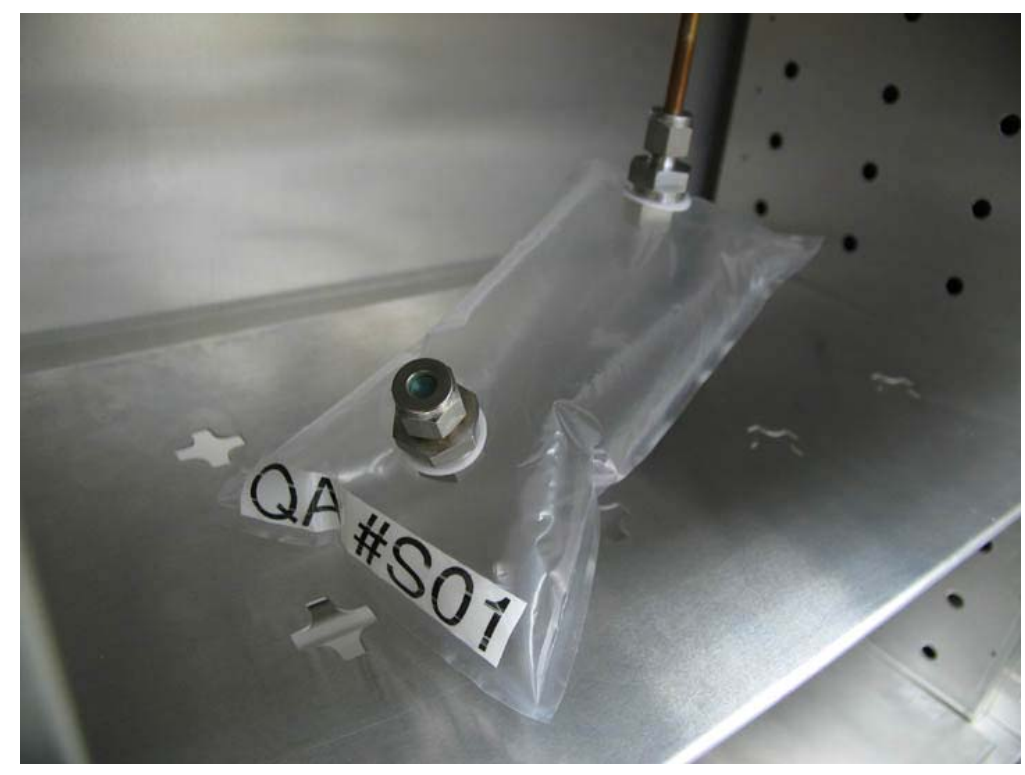

Figure 6.2. Sample Chamber Showing Tedlar Bag Used for Injecting Standards. It uses a Jenson Inert Products Tedlar ${ }^{\circledR}$ Gas Sampling Bag with two $1 / 4$-inch Stainless Steel Swagelok ${ }^{\circledR}$ Fittings. One fitting is connected to the input/output of the sample chamber and the other is fitted with a butyl rubber septum for standard introduction using a Hamilton 10- $\mu$ l syringe. 
6.3 Storage of a permeation source at the EFL is limited to those times when calibration checks are scheduled or required by observed drift in the retention times of ubiquitous halocarbons. ${ }^{(a)}$ When not required, the permeation source is moved to a laboratory in an adjacent corner of the EFL facility. Standards used to make the permeation sources are stored in a different building to minimize possible contamination of the ambient air.

6.4 Validation studies have shown that analyte retention times for the ODC analysis system are stable for several weeks. However, retention time checks with the ODC mixture should be conducted at the start and end of every week, or at the beginning and ending of every five circuit board sample set, to document that retention times were stable during the analysis period. More frequent checks should be conducted when the retention times of ubiquitous materials (methylene chloride, trichloroethylene and tetrachloroethylene), which are used as internal standards, indicate any significant drift in retention times.

6.5 In addition to analyte retention time checks, helium purge gas samples are also examined to demonstrate gas purity and the absence of sample bag memory effects. Tedlar bags used for circuit board purge experiments are never exposed to the headspace vapors used for retention time checks. These bags are, however, reused for the examination of circuit boards and the absence of analyte memory is demonstrated by purge gas analysis with the empty bags before their reuse. System and purge gas tests are described in Table 6.2. System blanks enable sample bags exposed to residual solvents from previous circuit board samples to be examined before reuse. These blanks are performed with the sample chamber at the elevated temperature of $40^{\circ} \mathrm{C}$.

Table 6.2. Purge Gas and System Blanks

\begin{tabular}{|l|l||}
\hline \multicolumn{1}{|c|}{ Blank } & \multicolumn{1}{c|}{ Description } \\
\hline Purge gas (instrument blank) & $\begin{array}{l}\text { Cryogenic collection of purge gas with the sample } \\
\text { chamber valve in the chamber bypass position }\end{array}$ \\
\hline System blank & $\begin{array}{l}\text { Cryogenic sample collection with purge gas flow } \\
\text { through an empty Tedlar bag }\end{array}$ \\
\hline
\end{tabular}

6.6 Quality assurance (QA) samples, circuit boards that have been previously tested and have known volatile chemical contamination, are included in the analysis sequence for all materials submitted for analysis. One QA sample, randomly inserted in to the analysis sequence, is included with every four circuit board samples.

(a) Halocarbons are found in essentially all samples by virtue of their significant ambient concentrations arising from their extensive industrial use. For instance, trichloroethylene and tetrachloroethylene have been found in all purge gas samples from new, unused Tedlar bags. Their presence in the purge gas from circuit board samples is a consequence of residual material from the Tedlar bag, exposure of circuit board components during fabrication, as well as finite levels from the ambient atmosphere not completely purged from the Tedlar bag before sample collection. 
6.7 The composition of the September 13, 2005, permeation source is recorded in Table 6.3. This mixture contains a total of 15 halocarbons, including cis and trans isomers of 1,2-dichloroethylene and 1,3-dichloropropene. It includes five materials identified as Class I Ozone Depleting Chemicals and two Freon replacements (chlorofluorohydrocarbons) that have already (HCFC141b) or will be phased out of production by 2015 (HCFC-225). A chromatogram of a purge gas sample from the sample chamber holding the September 13, 2005, permeation source is shown in Figure 6.3. Variations in permeation rates and the purge time before sample collection account for differences in the observed peak areas. The chromatogram in Figure 6.3 is representative of this permeation source.

Table 6.3. Halocarbon Composition of September 13, 2005, Permeation Source. Class I Ozone Depleting Chemicals are highlighted.

\begin{tabular}{||l|l||}
\hline \multicolumn{1}{|c|}{ Analyte } & \multicolumn{1}{c|}{ CAS } \\
\hline methylene chloride & $75-09-2$ \\
\hline 1,1-dichloro-1-fluoroethane(HCFC141b) & $1717-00-6$ \\
\hline dichlorohexafluoropropane(CFC216) & $661-97-2$ \\
\hline 1,3-dichloro-1,1,2,2,3pentafluoropropane(HCFC225cb) & $507-55-1$ \\
\hline 1,1,2-trichloro-trifluoroethanne(CFC113) & $76-13-1$ \\
\hline chloroform & $67-66-3$ \\
\hline 1,2-dichloroethylene (cis \& trans isomers) & $156-59-2$ \\
\hline 1,1,1-trichloroethane & $71-55-6$ \\
\hline carbon tetrachloride & $56-23-5$ \\
\hline 1,2-difluoro-1,1,2,2-tetrachloroethane(CFC112) & $76-12-0$ \\
\hline 1,3-dichloropropene (cis \& trans isomers) & $542-75-6$ \\
\hline 1,1,2-trichloroethanne & $79-00-5$ \\
\hline tetrachloroethylene & $127-18-4$ \\
\hline
\end{tabular}



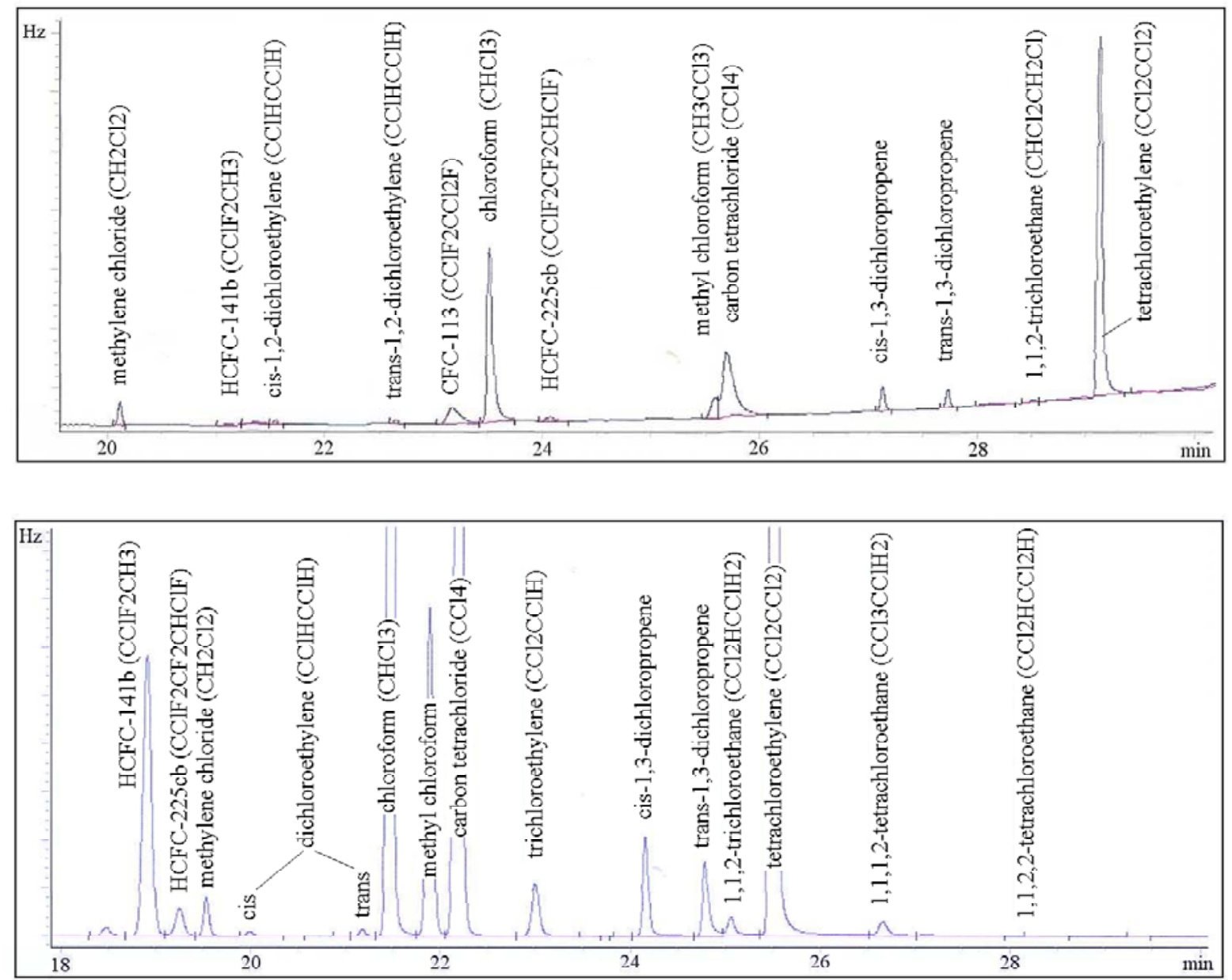

Figure 6.3. Chromatograms of Purge Gas Sample from September 13, 2005, Permeation Source Using Analysis Methods A (top) and B (bottom) 



\subsection{ODC System Stand-by}

The column oven temperature is raised to $100^{\circ} \mathrm{C}$ when the system is not in use to prevent trace carrier gas contaminants from accumulating in the column and increasing the baseline signal when the system is brought back on-line for analysis. All other method set points, including the cryotrap upper temperature of $100^{\circ} \mathrm{C}$, remain unchanged during stand-by. The column temperature is reduced to $30^{\circ} \mathrm{C}$ when the stand-by time exceeds 5 days. 



\subsection{Data System Preparation}

Files containing data for all sample analysis and associated standards are stored sequentially in subdirectories identified by the date the work was conducted. Data are initially stored on the ChemStation computer, but after review are copied to the EFL server. Specific information, unique to each analysis, is recorded electronically in the sample information window accessed through the 'Run Control' menu in the 'Instrument (on-line): Method and Run Control' window of ChemStation. This information duplicates hand recorded information on the 'ODC-GC Daily Sample Log'. The subdirectory name consists of seven characters formed from a three letter abbreviation for the month, two digits for the day of the month and the last two digits of the year. For example, data acquired from analyses performed on January 9, 2007, are stored in subdirectory JAN0907. Specific information about the sample (product identification or standard type and analysis conditions) is included with the electronic data file. This information and notes verifying that analyses were performed in accordance with this protocol are hand recorded by the operator (Daily Sample Log). These handwritten notes must include:

- product identification (with Tedlar bag identification) or sample type (external standard, instrument blank or system blank, with Tedlar bag identification),

- GC data file,

- date of analysis, and

- sample temperature.

The Daily Sample Log, with operator signature, is stored with the analysis reports generated by ChemStation and filed in folders in the ODC Data File. 



\subsection{Sample Sequence}

9.1 After the bag has been inflated with helium, allow a minimum of 45 minutes for ambient air to be flushed from the bag before initiating sample collection. As a minimum, the number of analyses associated with a given PCB is four- two at room temperature and two at $40^{\circ} \mathrm{C}$. Residual solvents in the circuit board matrix are revealed by peak area trends observed over the sample injection sequence described in Table 9.1. The GC sequence tables shown in Appendix A automate these functions for the two different GC column methods. A reproducible baseline signal must be observed for two consecutive purge gas samples with the sample chamber at room temperature before raising the chamber temperature to $40^{\circ} \mathrm{C}$. This approach further ensures that measured ODCs are degassed from the circuit board.

Table 9.1. Injection Sequence for Residual ODC Detection in Circuit Board Sample

\begin{tabular}{|c|c|l||}
\hline $\begin{array}{c}\text { Injection } \\
\text { Number }\end{array}$ & $\begin{array}{c}\text { Chamber } \\
\text { Temperature }\end{array}$ & \multicolumn{1}{c||}{ Chromatogram Description } \\
\hline 1 & $\sim 23^{\circ} \mathrm{C}$ & $\begin{array}{l}\text { This is a baseline chromatogram of the purge gas sample from the } \\
\text { Tedlar containing a PCB at room temperature. }\end{array}$ \\
\hline 2 & $\sim 23^{\circ} \mathrm{C}$ & $\begin{array}{l}\text { If the second baseline chromatogram agrees with the first, increase } \\
\text { the temperature of the sample chamber to } 40^{\circ} \mathrm{C} \text {. If back-to-back } \\
\text { samples from the chamber at } \sim 23^{\circ} \mathrm{C} \text { do not show good agreement, } \\
\text { continue to examine purge gas from the chamber at } \sim 23^{\circ} \mathrm{C} \text { until the } \\
\text { respective peak areas in the back-to-back chromatograms } \\
\text { (prominent halocarbons and ODC peaks) agree within } ~ 20 \% . \text { After } \\
\text { the chamber temperature has stabilized at } 40^{\circ} \mathrm{C} \text {, wait } 15 \text { minutes } \\
\text { before collection of the next purge gas sample. }\end{array}$ \\
\hline $3 \& 4$ & $40^{\circ} \mathrm{C}$ & $\begin{array}{l}\text { Solvent release from the circuit board will be accelerated at the } \\
\text { higher chamber temperature. The second purge gas sample from } \\
\text { the chamber at } 40^{\circ} \mathrm{C} \text { is taken to confirm peak area trends observed } \\
\text { with the first } 40^{\circ} \mathrm{C} \text { sample. }\end{array}$ \\
\hline \hline
\end{tabular}

9.2 At the end of the last purge gas sample analysis, the purge gas sample valve (V2) defaults to the "purge" position and Valve 1 defaults to the "sample" position. Thus, to minimize system contamination with ambient air, it is necessary to manually switch the purge gas sample valve (V2) to the "bypass" position before removing the Tedlar bag. Once a new bag is installed, manually switch V2 to the "purge" position to fill the sample bag with He and begin flushing ambient air from the bag.

9.3 The sequence of samples, blanks and qualitative standard analyses associated with a given set of samples is presented graphically in Table 9.2. 
Table 9.2. Analysis Sequence for a Set of Five Circuit Boards (1 QA and 4 new samples)

\begin{tabular}{|c|l|}
\hline I. & $\begin{array}{l}\text { Calibration (purge gas collection from sample chamber containing a } \\
\text { CFC/HCFC/halocarbon permeation source) (Method A or B). }\end{array}$ \\
\hline II. & $\begin{array}{l}\text { Instrument blank (purge gas sample obtained with the purge gas sample } \\
\text { valve in the bypass position) (Method A or B). }\end{array}$ \\
\hline III. & $\begin{array}{l}\text { System blank (purge gas through empty Tedlar bag at } 40^{\circ} \mathrm{C} \text { to be used for } \\
\text { circuit board sample) (Method A or B). }\end{array}$ \\
\hline IV. & $\begin{array}{l}\text { Insert circuit board into Tedlar bag for analysis and allow to purge at least } \\
45 \text { minutes (default position of valves). }\end{array}$ \\
\hline V. & $\begin{array}{l}\text { Circuit board sample analysis controlled by ChemStation Sequence Table } \\
\text { (series of four purge gas injections - a minimum of two with the sample at } \\
\sim 23^{\circ} \mathrm{C} \text { and two at } 40^{\circ} \mathrm{C} \text { ) (Sequence A or B). }\end{array}$ \\
\hline VI. & Remove Tedlar bag and replace with new empty bag. \\
\hline VII. & $\begin{array}{l}\text { Return to Step II for the analysis of a new circuit board. One sample is a } \\
\text { QA sample that is randomly positioned in the five-sample sequence. }\end{array}$ \\
\hline
\end{tabular}

9.4 The focus of this method is to identify ozone depleting chemicals released from a circuit board or other solid matrices under examination. Although other solvents may be found and reported with the preliminary results, the final report will be restricted to the ODC materials of interest as identified in IRS regulations. Table 9.3 lists the names and CAS numbers of these ODC materials. Only those chemicals that are liquids are considered relevant for use as cleaning agents during circuit board fabrication. A few of the liquid chemicals no longer have commercial sources. 
Table 9.3. Taxable Ozone Depleting Chemicals

\begin{tabular}{|l|l|l|c|c||}
\hline \multicolumn{1}{|c|}{ Chemical Name } & \multicolumn{1}{|c|}{$\begin{array}{c}\text { Chemical } \\
\text { Formula }\end{array}$} & \multicolumn{1}{|c|}{ CAS } & \multicolumn{1}{c||}{$\begin{array}{c}\text { Physical } \\
\text { State }\end{array}$} & Available \\
\hline CFC-11 & $\mathrm{CCl}_{3} \mathrm{~F}$ & {$[75-69-4]$} & gas & yes \\
\hline CFC-12 & $\mathrm{CCl}_{2} \mathrm{~F}_{2}$ & {$[75-71-8]$} & gas & yes \\
\hline CFC-13 & $\mathrm{CClF}_{3}$ & {$[75-72-9]$} & gas & yes \\
\hline CFC-111 & $\mathrm{C}_{2} \mathrm{Cl}_{5} \mathrm{~F}$ & {$[354-56-3]$} & solid & yes \\
\hline CFC-112 & $\mathrm{C}_{2} \mathrm{Cl}_{4} \mathrm{~F}_{2}$ & {$[76-12-0]$} & solid & yes \\
\hline CFC-113 & $\mathrm{C}_{2} \mathrm{Cl}_{3} \mathrm{~F}_{3}$ & {$[76-13-1]$} & liquid & yes \\
\hline CFC-114 & $\mathrm{C}_{2} \mathrm{Cl}_{2} \mathrm{~F}_{4}$ & {$[76-14-2]$} & gas & yes \\
\hline CFC-115 & $\mathrm{C}_{2} \mathrm{ClF}_{5}$ & {$[76-15-3]$} & gas & yes \\
\hline CFC-211 & $\mathrm{C}_{3} \mathrm{ClF}_{7}$ & {$[422-78-6]$} & liquid & no \\
\hline CFC-212 & $\mathrm{C}_{3} \mathrm{Cl}_{6} \mathrm{~F}_{2}$ & {$[3182-26-1]$} & liquid & no \\
\hline CFC-213 & $\mathrm{C}_{3} \mathrm{Cl}_{5} \mathrm{~F}_{3}$ & {$[2354-06-5]$} & liquid & no \\
\hline CFC-214 & $\mathrm{C}_{3} \mathrm{Cl}_{4} \mathrm{~F}_{4}$ & {$[29255-31-0]$} & liquid & no \\
\hline CFC-215 & $\mathrm{C}_{3} \mathrm{Cl}_{3} \mathrm{~F}_{5}$ & {$[4259-43-2]$} & liquid & yes \\
\hline CFC-216 & $\mathrm{C}_{3} \mathrm{Cl}_{2} \mathrm{~F}_{6}$ & {$[661-97-2]$} & liquid & yes \\
\hline CFC-217 & $\mathrm{C}_{3} \mathrm{ClF}_{7}$ & {$[422-86-6]$} & gas & no \\
\hline Halon-1211 & $\mathrm{CBrClF}_{2}$ & {$[353-59-3]$} & gas & yes \\
\hline Halon-1301 & $\mathrm{CBrF}_{3}$ & {$[75-63-8]$} & gas & yes \\
\hline Halon-2402 & $\mathrm{C}_{2} \mathrm{Br}_{2} \mathrm{~F}_{4}$ & {$[124-73-2]$} & liquid & yes \\
\hline Carbon Tetrachloride & $\mathrm{CCl}_{4}$ & {$[56-23-5]$} & liquid & yes \\
\hline Methyl Chloroform & $\mathrm{CH}_{3} \mathrm{Cl}_{3}$ & {$[71-55-6]$} & liquid & yes \\
\hline \hline
\end{tabular}





\subsection{Data Analysis}

10.1 Overlaying chromatograms for purge gas samples collected under baseline conditions (sample chamber at $\left.\sim 23^{\circ} \mathrm{C}\right)$ and at an elevated temperature $\left(40^{\circ} \mathrm{C}\right)$ allows immediate visual identification of residual volatile chemicals. A copy of overlaid chromatograms for a circuit board containing the ODC methyl chloroform is shown in Figure 10.1.

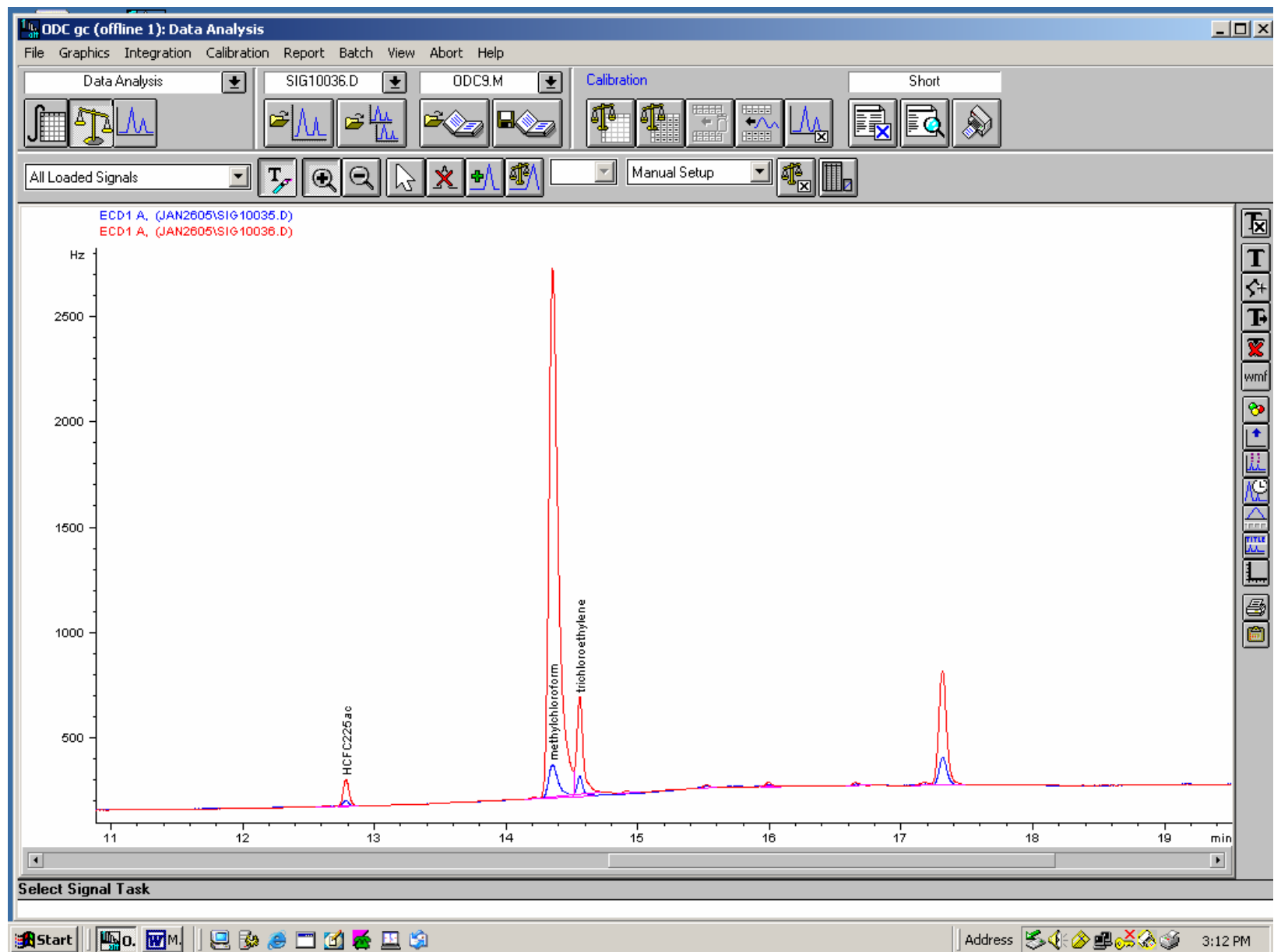

Figure 10.1. Overlaid Chromatograms Demonstrating the Effect of Temperature on Analyte Peak Areas with a Circuit Board Sample at Room Temperature (blue trace) and $35^{\circ} \mathrm{C}$ (red trace)

10.2 Calculate the sample volume normalized ODC peak areas for analyte purge gas samples at $23^{\circ} \mathrm{C}$ and $40^{\circ} \mathrm{C}$, respectively. The volume normalized peak area is calculated by first measuring the flow rate in milliliters per minute then multiplying that number by the total sample time in minutes. These parameters are set by the method and controlled by the computer, so they are constant. The resulting value or total sample volume is then used to calculate the volume normalized peak area by dividing each peak area measurement for a particular run with the total sample volume for that run. 
10.3 Calculate the relative peak area using the volume normalized peak area. The relative peak area is the volume normalized peak area of a run in an analysis divided by the average of the volume normalized peak areas of two runs at room temperature from that analysis. Thus, each run in an analysis is normalized to the average of two runs at room temperature. The results of which are plotted against each other allowing for straightforward normalized data interpretation and reporting.

10.4 With fully automated operation, the peak areas of the specific peaks of interest are exported to Excel, the calculations performed, and the results graphed as shown in Figure 5.2. A copy of the Excel spreadsheet is shown in Appendix E. An Excel macro is used to automatically create the graphs. 


\section{Appendix A}

\section{GC Method Sequence Tables}





\section{Appendix A}

\section{GC Method Sequence Tables}

\section{Sequence A}

Sequence Parameters:

Operator:

Data File Naming: Prefix/Counter

Signal 1 Prefix: SID1

Counter: 000001

Signal 2 Prefix: SIG2

Counter: 000001

Data Directory:

Data Subdirectory:

Part of Methods to run: According to Runtime Checklist

Barcode Reader: not used

Shutdown Cmd/Macro: none

Sequence Comment:

Sequence Table (Front Injector):

Method and Injection Info Part:

\begin{tabular}{|c|c|c|c|c|c|}
\hline Line & Location & $\begin{array}{c}\text { Sample Name } \\
\text { DataFile LimsID }\end{array}$ & Method & Inj Sample Type & Inj Volume \\
\hline 1 & Vial 1 & instrument blank & METHOD A & 1 & Sample \\
\hline 2 & Vial 2 & S1, room temp, rep 1 & METHOD A & 1 & Sample \\
\hline 3 & Vial 3 & S1, room temp, rep 2 & METHOD A HTSP & 1 & Sample \\
\hline 4 & Vial 4 & $\mathrm{~S} 1,40^{\circ} \mathrm{C}$, rep 1 & METHOD A & 1 & Sample \\
\hline 5 & Vial 5 & $\mathrm{~S} 1,40^{\circ} \mathrm{C}$, rep 2 & METHOD A LTSP & 1 & Sample \\
\hline
\end{tabular}

Sequence Table (Back Injector):

No entries - empty table!

Sequence Output Parameters:

Print Sequence Summary Report (SSR):

$\mathrm{N}$

Dest of individual reports for each run:

As specified in Method

Sequence Summary Parameters:

One page header:

No 
Print Configuration: No

Print Sequence: No

Print Logbook: No

Print Method(s): No

Print Analysis reports: No

Print Statistics for Calib. runs: No

Print Statistics for Sample runs: No

Summary style: Sample Summary

\section{Sequence B}

Sequence Parameters:

Operator:

Data File Naming: Prefix/Counter

Signal 1 Prefix: SID1

Counter: 000001

Signal 2 Prefix: SIG2

Counter: 000001

Data Directory:

Data Subdirectory:

Part of Methods to run: According to Runtime Checklist

Barcode Reader: not used

Shutdown Cmd/Macro: none

Sequence Comment:

Sequence Table (Front Injector):

Method and Injection Info Part:

\begin{tabular}{|c|c|c|c|c|c|}
\hline Line & Location & $\begin{array}{c}\text { Sample Name } \\
\text { DataFile LimsID }\end{array}$ & Method & Inj Sample Type & Inj Volume \\
\hline 1 & Vial 1 & instrument blank & METHOD B & 1 & Sample \\
\hline 2 & Vial 2 & S1, room temp, rep 1 & METHOD B & 1 & Sample \\
\hline 3 & Vial 3 & S1, room temp, rep 2 & METHOD B HTSP & 1 & Sample \\
\hline 4 & Vial 4 & $\mathrm{~S} 1,40^{\circ} \mathrm{C}$, rep 1 & METHOD B & 1 & Sample \\
\hline 5 & Vial 5 & $\mathrm{~S} 1,40^{\circ} \mathrm{C}$, rep 2 & METHOD B LTSP & 1 & Sample \\
\hline
\end{tabular}

Sequence Table (Back Injector):

No entries - empty table!

Sequence Output Parameters:

Print Sequence Summary Report (SSR): N

Dest of individual reports for each run: As specified in Method 
Sequence Summary Parameters:

One page header: No

Print Configuration: No

Print Sequence: No

Print Logbook: No

Print Method(s): No

Print Analysis reports: No

Print Statistics for Calib. runs: No

Print Statistics for Sample runs: No

Summary style: Sample Summary 



\section{Appendix B}

\section{Method A Information}





\section{Appendix B}

\section{Method A Information}

Method: C:\METHODS $\backslash$ METHOD A.M

Modified:

Method A: Main GC method for ODC-GC1 with column 1

$\underline{\text { Run Time Checklist }}$

Pre-Run Cmd/Macro: off

Data Acquisition: on

Standard Data Analysis: on

Customized Data Analysis: off

Save GLP Data: off

Post-Run Cmd/Macro: off

Save Method with Data: on

\section{GC METHOD}

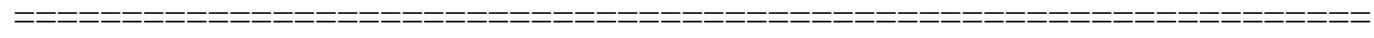

OVEN

Initial temp: $30^{\circ} \mathrm{C}(\mathrm{On})$

Maximum temp: $280^{\circ} \mathrm{C}$

Initial time: $16.00 \mathrm{~min}$

Ramps:

\# Rate Final temp Final time CRYO (N2)

$1 \quad 100.00 \quad 80^{\circ} \mathrm{C} \quad 0.00 \quad$ Cryo: Off

$28.00 \quad 216^{\circ} \mathrm{C} \quad 5.00 \quad$ Cryo fault: Off

$3 \quad 0.0$ (Off)

Post temp: $50^{\circ} \mathrm{C}$

Post time: $0.00 \mathrm{~min}$

Quick cryo cool: Off

Cryo timeout: $120.00 \mathrm{~min}$ (Off)

Ambient temp: $25^{\circ} \mathrm{C}$ 
FRONT INLET (UNKNOWN)

COLUMN 1

Capillary Column

Model Number: Varian CP7384

PoraBond Q

Max temperature: $280^{\circ} \mathrm{C}$

Nominal length: $25.0 \mathrm{~m}$

Nominal diameter: $250.00 \mu \mathrm{m}$

Nominal film thickness: $3.00 \mu \mathrm{m}$

Mode: constant flow

Initial flow: $1.8 \mathrm{~mL} / \mathrm{min}$

Nominal init pressure: $16.00 \mathrm{psi}$

Average velocity: $40 \mathrm{~cm} / \mathrm{sec}$

Inlet: Aux 4 Pressure Controller

Outlet: Front Detector

Outlet pressure: ambient

FRONT DETECTOR ( $\mu$ ECD)

Temperature: $250^{\circ} \mathrm{C}$ (On)

Mode: Constant makeup flow

Makeup flow: $60.0 \mathrm{~mL} / \mathrm{min}$ (On)

Makeup Gas Type: Nitrogen

Electrometer: On

SIGNAL 1

Data rate: $20 \mathrm{~Hz}$

Type: front detector

Save Data: On

Zero: 0.0 (Off)

Range: 0

Fast Peaks: Off

Attenuation: 0

\section{COLUMN COMP 1}

Derive from front detector

\section{THERMAL AUX 1}

Use: Valve Box Heater

Description:

Initial temp: $100^{\circ} \mathrm{C}(\mathrm{On})$

Initial time: $0.00 \mathrm{~min}$

\# Rate Final temp Final time

10.0 (Off)

\section{BACK INLET (UNKNOWN)}

COLUMN 2

(not installed)

BACK DETECTOR (NO DET)

SIGNAL 2

Data rate: $20 \mathrm{~Hz}$

Type: front detector

Save Data: Off

Zero: 0.0 (Off)

Range: 0

Fast Peaks: Off

Attenuation: 0

\section{COLUMN COMP 2}

Derive from front detector

\section{AUX PRESSURE 3}

Description:

Gas Type: Helium

Initial pressure: 0.00 psi (Off) 
AUX PRESSURE 4

Description: Carrier Gas

Gas Type: Helium

Driving Column 1

Initial pressure: 15.99 psi (On)
AUX PRESSURE 5

Description: Purge Gas

Gas Type: Helium

Initial pressure: $20.00 \mathrm{psi}(\mathrm{On})$

Initial time: $0.00 \mathrm{~min}$

\# Rate Final pres Final time

10.0 (Off)

POST RUN

Post Time: $0.00 \mathrm{~min}$
VALVES

Valve 1 Gas Sampling

Description:

Loop Volume: $1.000 \mathrm{~mL}$

Load Time: $1.00 \mathrm{~min}$

Inject Time: $3.00 \mathrm{~min}$

Inlet: Aux 4 Pressure Controller

Valve 6 Switching Off

Description:

Temperature control switches the set point temperature in the oven to set point 1 or set point 2 .

Valve 7 Switching Off

Description:

Cryo-Trap heating or cooling switch.

Valve 8 Switching Off

Description:

External VICI Valco sample valve.

TIME TABLE

$\begin{array}{clcc}\text { Time } & \text { Specifier } & \text { Parameter \& Setpoint } \\ 0.00 & \text { Aux 2 Temperature } 50^{\circ} \mathrm{C} & \\ 0.00 & \text { Valve 7: } & \text { On } & \\ 0.00 & \text { Valve 8: } & \text { Off } & \\ 3.00 & \text { Valve 8: } & \text { On } & \\ 13.00 & & \text { Valve 1: } & \text { On } \\ 13.00 & & \text { Valve 7: } & \text { Off } \\ 16.00 & \text { Valve 1: } & \text { Off } & \end{array}$

Front Injector:

No parameters specified

Back Injector:

No parameters specified 
Method: C:\METHODS $\backslash$ METHOD A HTSP.M

Modified:

Method A HTSP: High temperature set point method A. This method sets the sample chamber temperature to $40^{\circ} \mathrm{C}$ after the sample period.

\section{$\underline{\text { Run Time Checklist }}$}

Pre-Run Cmd/Macro: off

Data Acquisition: on

Standard Data Analysis: on

Customized Data Analysis: off

Save GLP Data: off

Post-Run Cmd/Macro: off

Save Method with Data: on

\begin{tabular}{|c|c|c|c|c|}
\hline \multicolumn{5}{|c|}{6890 GC METHOD } \\
\hline \multicolumn{5}{|c|}{ OVEN } \\
\hline \multicolumn{3}{|c|}{ Initial temp: $30^{\circ} \mathrm{C}(\mathrm{On})$} & \multicolumn{2}{|c|}{ Maximum temp: $280^{\circ} \mathrm{C}$} \\
\hline Initi & l time: 1 & $6.00 \mathrm{~min}$ & Equilibra & time: $0.50 \mathrm{~min}$ \\
\hline \multicolumn{5}{|c|}{ Ramps: } \\
\hline \# & Rate & Final temp & Final time & CRYO (N2) \\
\hline 1 & 100.00 & $80^{\circ} \mathrm{C}$ & 0.00 & Cryo: Off \\
\hline 2 & 8.00 & $216^{\circ} \mathrm{C}$ & 5.00 & Cryo fault: Off \\
\hline 3 & 0.0 (Off) & & & Cryo timeout: 120.00 min (Off) \\
\hline \multicolumn{3}{|c|}{ Post temp: $50^{\circ} \mathrm{C}$} & \multicolumn{2}{|c|}{ Quick cryo cool: Off } \\
\hline \multicolumn{3}{|c|}{ Post time: $0.00 \mathrm{~min}$} & \multicolumn{2}{|c|}{ Ambient temp: $25^{\circ} \mathrm{C}$} \\
\hline \multicolumn{5}{|c|}{ Run time: $38.50 \mathrm{~min}$} \\
\hline
\end{tabular}

FRONT INLET (UNKNOWN)

BACK INLET (UNKNOWN) 
COLUMN 1

Capillary Column

Model Number: Varian CP7384

PoraBond Q

Max temperature: $280^{\circ} \mathrm{C}$

Nominal length: $25.0 \mathrm{~m}$

Nominal diameter: $250.00 \mu \mathrm{m}$

Nominal film thickness: $3.00 \mu \mathrm{m}$

Mode: constant flow

Initial flow: $1.8 \mathrm{~mL} / \mathrm{min}$

Nominal init pressure: $16.00 \mathrm{psi}$

Average velocity: $40 \mathrm{~cm} / \mathrm{sec}$

Inlet: Aux 4 Pressure Controller

Outlet: Front Detector

Outlet pressure: ambient

FRONT DETECTOR ( $\mu$ ECD)

Temperature: $250^{\circ} \mathrm{C}$ (On)

Mode: Constant makeup flow

Makeup flow: $60.0 \mathrm{~mL} / \mathrm{min}$ (On)

Makeup Gas Type: Nitrogen

Electrometer: On

\section{SIGNAL 1}

Data rate: $20 \mathrm{~Hz}$

Type: front detector

Save Data: On

Zero: 0.0 (Off)

Range: 0

Fast Peaks: Off

Attenuation: 0

COLUMN COMP 1

Derive from front detector

\section{THERMAL AUX 1}

Use: Valve Box Heater

Description:

Initial temp: $100^{\circ} \mathrm{C}(\mathrm{On})$

Initial time: $0.00 \mathrm{~min}$

\# Rate Final temp Final time

10.0 (Off)
COLUMN 2

(not installed)
BACK DETECTOR (NO DET)

SIGNAL 2

Data rate: $20 \mathrm{~Hz}$

Type: front detector

Save Data: Off

Zero: 0.0 (Off)

Range: 0

Fast Peaks: Off

Attenuation: 0

\section{COLUMN COMP 2}

Derive from front detector

\section{AUX PRESSURE 3}

Description:

Gas Type: Helium

Initial pressure: 0.00 psi (Off) 
AUX PRESSURE 4

Description: Carrier Gas

Gas Type: Helium

Driving Column 1

Initial pressure: 15.99 psi (On)
AUX PRESSURE 5

Description: Purge Gas

Gas Type: Helium

Initial pressure: 20.00 psi (On)

Initial time: $0.00 \mathrm{~min}$

\# Rate Final pres Final time

10.0 (Off)

POST RUN

Post Time: $0.00 \mathrm{~min}$
VALVES

Valve 1 Gas Sampling

Description:

Loop Volume: $1.000 \mathrm{~mL}$

Load Time: $1.00 \mathrm{~min}$

Inject Time: $3.00 \mathrm{~min}$

Inlet: Aux 4 Pressure Controller

Valve 6 Switching Off

Description:

Temperature control switches the set point temperature in the oven to set point 1 or set point 2 .

Valve 7 Switching Off

Description:

Cryo-Trap heating or cooling switch.

Valve 8 Switching Off

Description:

External VICI Valco sample valve.

TIME TABLE

\begin{tabular}{clll} 
Time & Specifier & \multicolumn{2}{l}{ Parameter \& Setpoint } \\
0.00 & Aux 2 Temperature & $50^{\circ} \mathrm{C}$ & \\
0.00 & & Valve 7: & On \\
0.00 & Valve 8: & Off \\
3.00 & Valve 8: & On \\
13.00 & Valve 1: & On \\
13.00 & Valve 6: & On \\
13.00 & Valve 7: & Off \\
16.00 & Valve 1: & Off
\end{tabular}

GC Injector

Front Injector:

No parameters specified

Back Injector:

No parameters specified 


\section{Method A LTSP Information}

Method: C:IMETHODS\METHOD A LTSP.M

Modified:

Method A HTSP: Low temperature set point method A. This method sets the sample chamber temperature to room temperature after the sample period.

$\underline{\text { Run Time Checklist }}$

Pre-Run Cmd/Macro: off

Data Acquisition: on

Standard Data Analysis: on

Customized Data Analysis: off

Save GLP Data: off

Post-Run Cmd/Macro: off

Save Method with Data: on

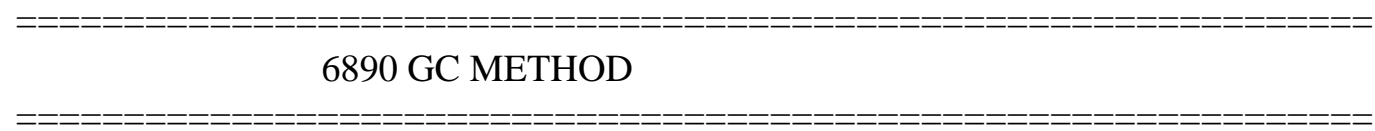

OVEN

Initial temp: $30^{\circ} \mathrm{C}(\mathrm{On})$

Initial time: $16.00 \mathrm{~min}$

Ramps:

\# Rate Final temp Final time CRYO (N2)

$\begin{array}{lllll}1 & 100.00 & 80^{\circ} \mathrm{C} & 0.00 & \text { Cryo: Off }\end{array}$

$2 \quad 8.00 \quad 216^{\circ} \mathrm{C} \quad 5.00$

$3 \quad 0.0$ (Off)

Post temp: $50^{\circ} \mathrm{C}$

Post time: $0.00 \mathrm{~min}$

Run time: $38.50 \mathrm{~min}$

FRONT INLET (UNKNOWN)
Maximum temp: $280^{\circ} \mathrm{C}$

Equilibration time: $0.50 \mathrm{~min}$

Cryo fault: Off

Cryo timeout: $120.00 \mathrm{~min}$ (Off)

Quick cryo cool: Off

Ambient temp: $25^{\circ} \mathrm{C}$

BACK INLET (UNKNOWN) 
COLUMN 1

Capillary Column

Model Number: Varian CP7384

PoraBond Q

Max temperature: $280^{\circ} \mathrm{C}$

Nominal length: $25.0 \mathrm{~m}$

Nominal diameter: $250.00 \mu \mathrm{m}$

Nominal film thickness: $3.00 \mu \mathrm{m}$

Mode: constant flow

Initial flow: $1.8 \mathrm{~mL} / \mathrm{min}$

Nominal init pressure: $16.00 \mathrm{psi}$

Average velocity: $40 \mathrm{~cm} / \mathrm{sec}$

Inlet: Aux 4 Pressure Controller

Outlet: Front Detector

Outlet pressure: ambient

FRONT DETECTOR ( $\mu$ ECD)

Temperature: $250^{\circ} \mathrm{C}$ (On)

Mode: Constant makeup flow

Makeup flow: $60.0 \mathrm{~mL} / \mathrm{min}$ (On)

Makeup Gas Type: Nitrogen

Electrometer: On

\section{SIGNAL 1}

Data rate: $20 \mathrm{~Hz}$

Type: front detector

Save Data: On

Zero: 0.0 (Off)

Range: 0

Fast Peaks: Off

Attenuation: 0

COLUMN COMP 1

Derive from front detector

\section{THERMAL AUX 1}

Use: Valve Box Heater

Description:

Initial temp: 100 'C (On)

Initial time: $0.00 \mathrm{~min}$

\# Rate Final temp Final time

10.0 (Off)
COLUMN 2

(not installed)
BACK DETECTOR (NO DET)

SIGNAL 2

Data rate: $20 \mathrm{~Hz}$

Type: front detector

Save Data: Off

Zero: 0.0 (Off)

Range: 0

Fast Peaks: Off

Attenuation: 0

\section{COLUMN COMP 2}

Derive from front detector

\section{AUX PRESSURE 3}

Description:

Gas Type: Helium

Initial pressure: 0.00 psi (Off) 
AUX PRESSURE 4

Description: Carrier Gas

Gas Type: Helium

Driving Column 1

Initial pressure: 15.99 psi (On)
AUX PRESSURE 5

Description: Purge Gas

Gas Type: Helium

Initial pressure: $20.00 \mathrm{psi}(\mathrm{On})$

Initial time: $0.00 \mathrm{~min}$

\# Rate Final pres Final time

10.0 (Off)

POST RUN

Post Time: $0.00 \mathrm{~min}$
VALVES

Valve 1 Gas Sampling

Description:

Loop Volume: $1.000 \mathrm{~mL}$

Load Time: $1.00 \mathrm{~min}$

Inject Time: $3.00 \mathrm{~min}$

Inlet: Aux 4 Pressure Controller

Valve 6 Switching Off

Description:

Temperature control switches the set point temperature in the oven to set point 1 or set point 2 .

Valve 7 Switching Off

Description:

Cryo-Trap heating or cooling switch.

Valve 8 Switching Off

Description:

External VICI Valco sample valve.

TIME TABLE

\begin{tabular}{clll} 
Time & Specifier & \multicolumn{2}{l}{ Parameter \& Setpoint } \\
0.00 & Aux 2 Temperature & $50^{\circ} \mathrm{C}$ & \\
0.00 & & Valve 7: & On \\
0.00 & Valve 8: & Off \\
3.00 & Valve 8: & On \\
13.00 & Valve 1: & On \\
13.00 & Valve 6: & Off \\
13.00 & Valve 7: & Off \\
16.00 & Valve 1: & Off
\end{tabular}

GC Injector

Front Injector:

No parameters specified

Back Injector:

No parameters specified 



\title{
Appendix C
}

\author{
Method B Information
}





\section{Appendix C}

\section{Method B Information}

Method: C:IMETHODS $\backslash$ METHOD B.M

Modified:

Method B: Main method for ODC-GC 2 with column 2

$\underline{\text { Run Time Checklist }}$

Pre-Run Cmd/Macro: off

Data Acquisition: on

Standard Data Analysis: on

Customized Data Analysis: off

Save GLP Data: off

Post-Run Cmd/Macro: off

Save Method with Data: on

\begin{tabular}{|c|c|c|c|c|}
\hline \multicolumn{5}{|c|}{ 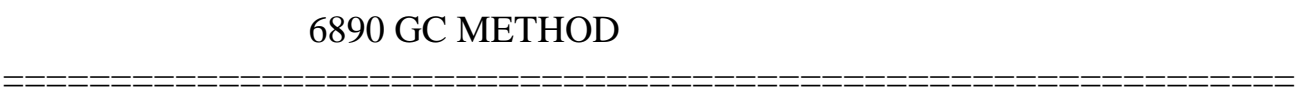 } \\
\hline \multicolumn{5}{|c|}{ OVEN } \\
\hline \multicolumn{3}{|c|}{ Initial temp: $-20^{\circ} \mathrm{C}(\mathrm{On})$} & \multicolumn{2}{|c|}{ Maximum temp: $240^{\circ} \mathrm{C}$} \\
\hline \multicolumn{3}{|c|}{ Initial time: $16.00 \mathrm{~min}$} & \multicolumn{2}{|c|}{ Equilibration time: $1.00 \mathrm{~min}$} \\
\hline \multicolumn{5}{|c|}{ Ramps: } \\
\hline \# & Rate & Final temp & Final time & CRYO (N2) \\
\hline 1 & 100.00 & $30^{\circ} \mathrm{C}$ & 0.00 & Cryo: On \\
\hline 2 & 10.00 & $200^{\circ} \mathrm{C}$ & 4.00 & Cryo fault: Off \\
\hline 3 & 0.0 (Off) & & & Cryo timeout: $120.00 \min$ (Off) \\
\hline \multicolumn{3}{|c|}{ Post temp: $30^{\circ} \mathrm{C}$} & \multicolumn{2}{|c|}{ Quick cryo cool: On } \\
\hline \multicolumn{3}{|c|}{ Post time: $0.00 \mathrm{~min}$} & \multicolumn{2}{|c|}{ Ambient temp: $30^{\circ} \mathrm{C}$} \\
\hline \multicolumn{5}{|c|}{ Run time: $37.70 \mathrm{~min}$} \\
\hline
\end{tabular}


COLUMN 1

Capillary Column

Model Number: Restek-624

RTX-624

Max temperature: $280^{\circ} \mathrm{C}$

Nominal length: $30.0 \mathrm{~m}$

Nominal diameter: $320.00 \mu \mathrm{m}$

Nominal film thickness: $5.00 \mu \mathrm{m}$

Mode: constant flow

Initial flow: $1.5 \mathrm{~mL} / \mathrm{min}$

Nominal init pressure: $5.92 \mathrm{psi}$

Average velocity: $23 \mathrm{~cm} / \mathrm{sec}$

Inlet: Aux 4 Pressure Controller

Outlet: Front Detector

Outlet pressure: ambient

FRONT DETECTOR ( $\mu$ ECD)

Temperature: $250^{\circ} \mathrm{C}$ (On)

Mode: Constant makeup flow

Makeup flow: $60.0 \mathrm{~mL} / \mathrm{min}$ (On)

Makeup Gas Type: Nitrogen

Electrometer: On

SIGNAL 1

Data rate: $10 \mathrm{~Hz}$

Type: front detector

Save Data: On

Zero: 0.0 (Off)

Range: 0

Fast Peaks: Off

Attenuation: 0

COLUMN COMP 1

Derive from front detector

THERMAL AUX 1

Use: Valve Box Heater

Description:

Initial temp: $100^{\circ} \mathrm{C}(\mathrm{On})$

Initial time: $0.00 \mathrm{~min}$

\# Rate Final temp Final time

10.0 (Off)
COLUMN 2

(not installed)
BACK DETECTOR (NO DET)

SIGNAL 2

Data rate: $20 \mathrm{~Hz}$

Type: front detector

Save Data: Off

Zero: 0.0 (Off)

Range: 0

Fast Peaks: Off

Attenuation: 0

COLUMN COMP 2

Derive from front detector

AUX PRESSURE 3

Description:

Gas Type: Helium

Initial pressure: 8.00 psi (Off) 
AUX PRESSURE 4

Description: Carrier Gas

Gas Type: Helium

Driving Column 1

Initial pressure: $5.92 \mathrm{psi}(\mathrm{On})$

VALVES

Valve 1 Gas Sampling

Description:

Loop Volume: $1.000 \mathrm{~mL}$

Load Time: $10.00 \mathrm{~min}$

Inject Time: $3.00 \mathrm{~min}$

Inlet: Aux 4 Pressure Controller

Valve 6 Switching Off

Description:

Temperature control switches the set point temperature in the oven to set point 1 or set point 2 .

Valve 7 Switching Off

Description:

Cryo-Trap heating or cooling switch.

Valve 8 Switching Off

Description:

External VICI Valco sample valve.

TIME TABLE

\begin{tabular}{crrr} 
Time & Specifier & \multicolumn{2}{c}{ Parameter \& Setpoint } \\
0.00 & Aux 2 Temperature & $50^{\circ} \mathrm{C}$ & \\
0.00 & & Valve 7: & On \\
0.00 & & Valve 8: & Off \\
3.00 & Valve 8: & On \\
13.00 & Valve 1: & On \\
13.00 & Valve 7: & Off \\
16.00 & Valve 1: & Off
\end{tabular}

AUX PRESSURE 5

Gas Type: Helium

Initial pressure: $20.00 \mathrm{psi}$ (On)

Initial time: $0.00 \mathrm{~min}$

\# Rate Final pres Final time

10.0 (Off)

POST RUN

Post Time: $0.00 \mathrm{~min}$
Description: Purge Gas

\section{GC Injector}

Front Injector:

No parameters specified

Back Injector:

No parameters specified 


\section{Method B HTSP Information}

Method: C:IMETHODS $\backslash$ METHOD B HTSP.M

Modified:

Method B HTSP: High temperature set point method B. This method sets the sample chamber temperature to $40 \mathrm{C}$ after the sample period.

$\underline{\text { Run Time Checklist }}$

Pre-Run Cmd/Macro: off

Data Acquisition: on

Standard Data Analysis: on

Customized Data Analysis: off

Save GLP Data: off

Post-Run Cmd/Macro: off

Save Method with Data: on

\begin{tabular}{|c|c|c|c|c|}
\hline \multicolumn{5}{|c|}{6890 GC METHOD } \\
\hline \multicolumn{5}{|c|}{ OVEN } \\
\hline \multicolumn{3}{|c|}{ Initial temp: $-20^{\circ} \mathrm{C}(\mathrm{On})$} & \multicolumn{2}{|c|}{ Maximum temp: $240^{\circ} \mathrm{C}$} \\
\hline \multirow{2}{*}{\multicolumn{3}{|c|}{$\begin{array}{l}\text { Initial time: } 16.00 \text { min } \\
\text { Ramps: }\end{array}$}} & \multicolumn{2}{|c|}{ Equilibration time: $1.00 \mathrm{~min}$} \\
\hline & & & \\
\hline \# & Rate & Final temp & Final time & CRYO (N2) \\
\hline 1 & 100.00 & $30^{\circ} \mathrm{C}$ & 0.00 & Cryo: On \\
\hline 2 & 10.00 & $200^{\circ} \mathrm{C}$ & 4.00 & Cryo fault: Off \\
\hline 3 & 0.0 (Off) & & & Cryo timeout: 120.00 min (Off) \\
\hline \multicolumn{3}{|c|}{ Post temp: $30^{\circ} \mathrm{C}$} & \multicolumn{2}{|c|}{ Quick cryo cool: On } \\
\hline \multicolumn{3}{|c|}{ Post time: $0.00 \mathrm{~min}$} & \multicolumn{2}{|c|}{ Ambient temp: $30^{\circ} \mathrm{C}$} \\
\hline \multicolumn{5}{|c|}{ Run time: $37.50 \mathrm{~min}$} \\
\hline
\end{tabular}


COLUMN 1

Capillary Column

Model Number: Restek RTX-624

RTX-624

Max temperature: $280^{\circ} \mathrm{C}$

Nominal length: $30.0 \mathrm{~m}$

Nominal diameter: $250.00 \mu \mathrm{m}$

Nominal film thickness: $1.40 \mu \mathrm{m}$

Initial flow: $1.5 \mathrm{~mL} / \mathrm{min}$

Nominal init pressure: 10.13 psi

Average velocity: $30 \mathrm{~cm} / \mathrm{sec}$

Inlet: Aux 4 Pressure Controller

Outlet: Front Detector

Outlet pressure: ambient

FRONT DETECTOR ( $\mu$ ECD)

Temperature: $250^{\circ} \mathrm{C}$ (On)

Mode: Constant makeup flow

Makeup flow: $60.0 \mathrm{~mL} / \mathrm{min}$ (On)

Makeup Gas Type: Nitrogen

Electrometer: On

\section{SIGNAL 1}

Data rate: $10 \mathrm{~Hz}$

Type: front detector

Save Data: On

Zero: 0.0 (Off)

Range: 0

Fast Peaks: Off

Attenuation: 0

COLUMN COMP 1

Derive from front detector

\section{THERMAL AUX 1}

Use: Valve Box Heater

Description:

Initial temp: $100^{\circ} \mathrm{C}(\mathrm{On})$

Initial time: $0.00 \mathrm{~min}$

\# Rate Final temp Final time

10.0 (Off)
COLUMN 2

(not installed)
BACK DETECTOR (NO DET)

SIGNAL 2

Data rate: $20 \mathrm{~Hz}$

Type: front detector

Save Data: Off

Zero: 0.0 (Off)

Range: 0

Fast Peaks: Off

Attenuation: 0

\section{COLUMN COMP 2}

Derive from front detector

\section{AUX PRESSURE 3}

Description:

Gas Type: Helium

Initial pressure: 8.00 psi (Off) 
AUX PRESSURE 4

Description: Carrier Gas

Gas Type: Helium

Driving Column 1

Initial pressure: 10.13 psi (On)
AUX PRESSURE 5

Description: Purge Gas

Gas Type: Helium

Initial pressure: $20.00 \mathrm{psi}(\mathrm{On})$

Initial time: $0.00 \mathrm{~min}$

\# Rate Final pres Final time

10.0 (Off)

POST RUN

Post Time: $0.00 \mathrm{~min}$
VALVES

Valve 1 Gas Sampling

Description:

Loop Volume: $1.000 \mathrm{~mL}$

Load Time: $10.00 \mathrm{~min}$

Inject Time: $3.00 \mathrm{~min}$

Inlet: Aux 4 Pressure Controller

Valve 6 Switching Off

Description:

Temperature control switches the set point temperature in the oven to set point 1 or set point 2 .

Valve 7 Switching Off

Description:

Cryo-Trap heating or cooling switch.

Valve 8 Switching Off

Description:

External VICI Valco sample valve.

TIME TABLE

\begin{tabular}{clll} 
Time & Specifier & \multicolumn{2}{l}{ Parameter \& Setpoint } \\
0.00 & Aux 2 Temperature & $50^{\circ} \mathrm{C}$ & \\
0.00 & & Valve 7: & On \\
0.00 & Valve 8: & Off \\
3.00 & Valve 8: & On \\
13.00 & Valve 1: & On \\
13.00 & Valve 6: & On \\
13.00 & Valve 7: & Off \\
16.00 & Valve 1: & Off
\end{tabular}

Front Injector:

GC Injector

No parameters specified

Back Injector:

No parameters specified 


\section{Method B LTSP Information}

Method: C:IMETHODS $\backslash$ METHOD B LTSP.M

Modified:

Method B LTSP: Low temperature set point method B. This method sets the sample chamber temperature to room temperature after the sample period.

$\underline{\text { Run Time Checklist }}$

Pre-Run Cmd/Macro: off

Data Acquisition: on

Standard Data Analysis: on

Customized Data Analysis: off

Save GLP Data: off

Post-Run Cmd/Macro: off

Save Method with Data: on

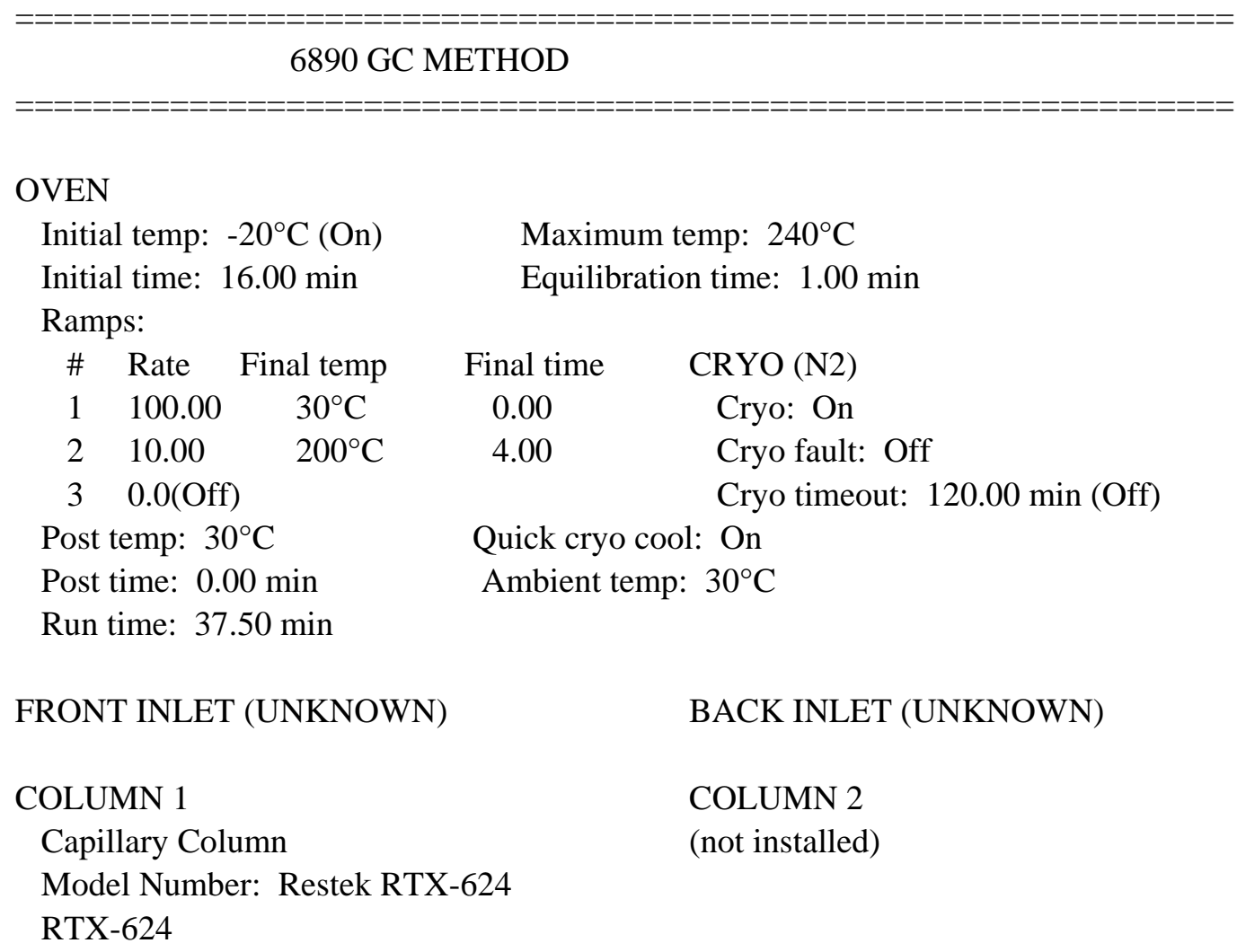


Max temperature: $280^{\circ} \mathrm{C}$

Nominal length: $30.0 \mathrm{~m}$

Nominal diameter: $250.00 \mu \mathrm{m}$

Nominal film thickness: $1.40 \mu \mathrm{m}$

Mode: constant flow

Initial flow: $1.5 \mathrm{~mL} / \mathrm{min}$

Nominal init pressure: $5.91 \mathrm{psi}$

Average velocity: $23 \mathrm{~cm} / \mathrm{sec}$

Inlet: Aux 4 Pressure Controller

Outlet: Front Detector

Outlet pressure: ambient

FRONT DETECTOR ( $\mu$ ECD)

Temperature: $250^{\circ} \mathrm{C}(\mathrm{On})$

Mode: Constant makeup flow

Makeup flow: $60.0 \mathrm{~mL} / \mathrm{min}$ (On)

Makeup Gas Type: Nitrogen

Electrometer: On

SIGNAL 1

Data rate: $10 \mathrm{~Hz}$

Type: front detector

Save Data: On

Zero: 0.0 (Off)

Range: 0

Fast Peaks: Off

Attenuation: 0

COLUMN COMP 1

Derive from front detector

THERMAL AUX 1

Use: Valve Box Heater

Description:

Initial temp: $100^{\circ} \mathrm{C}(\mathrm{On})$

Initial time: $0.00 \mathrm{~min}$

\# Rate Final temp Final time

10.0 (Off)

\section{AUX PRESSURE 4}

Description: Carrier Gas

Gas Type: Helium

Driving Column 1

Initial pressure: 5.91 psi (On)
BACK DETECTOR (NO DET)

SIGNAL 2

Data rate: $20 \mathrm{~Hz}$

Type: front detector

Save Data: Off

Zero: 0.0 (Off)

Range: 0

Fast Peaks: Off

Attenuation: 0

COLUMN COMP 2

Derive from front detector

\section{AUX PRESSURE 3}

Description:

Gas Type: Helium

Initial pressure: 8.00 psi (Off)
AUX PRESSURE 5

Description: Purge Gas

Gas Type: Helium

Initial pressure: $20.00 \mathrm{psi}(\mathrm{On})$

Initial time: $0.00 \mathrm{~min}$

\# Rate Final pres Final time

10.0 (Off) 
VALVES

Valve 1 Gas Sampling

Description:

Loop Volume: $1.000 \mathrm{~mL}$

Load Time: $10.00 \mathrm{~min}$

Inject Time: $3.00 \mathrm{~min}$

Inlet: Aux 4 Pressure Controller

Valve 6 Switching Off

Description:

Temperature control switches the set point temperature in the oven to set point 1 or set point 2 .

Valve 7 Switching Off

Description:

Cryo-Trap heating or cooling switch.

Valve 8 Switching Off

Description:

External VICI Valco sample valve.

\section{TIME TABLE}

\begin{tabular}{cccc} 
Time & Specifier & \multicolumn{2}{c}{ Parameter \& Setpoint } \\
0.00 & Aux 2 Temperature & $50^{\circ} \mathrm{C}$ & \\
0.00 & & Valve 7: & On \\
0.00 & & Valve 8: & Off \\
3.00 & & Valve 8: & On \\
13.00 & Valve 1: & On \\
13.00 & Valve 6: & Off \\
13.00 & Valve 7: & Off \\
16.00 & Valve 1: & Off
\end{tabular}

POST RUN

Post Time: $0.00 \mathrm{~min}$

\section{GC Injector}

Front Injector:

No parameters specified

Back Injector:

No parameters specified 

Appendix D

ODC-GC Daily Sample Log 



\section{Appendix D}

\section{ODC-GC Daily Sample Log}

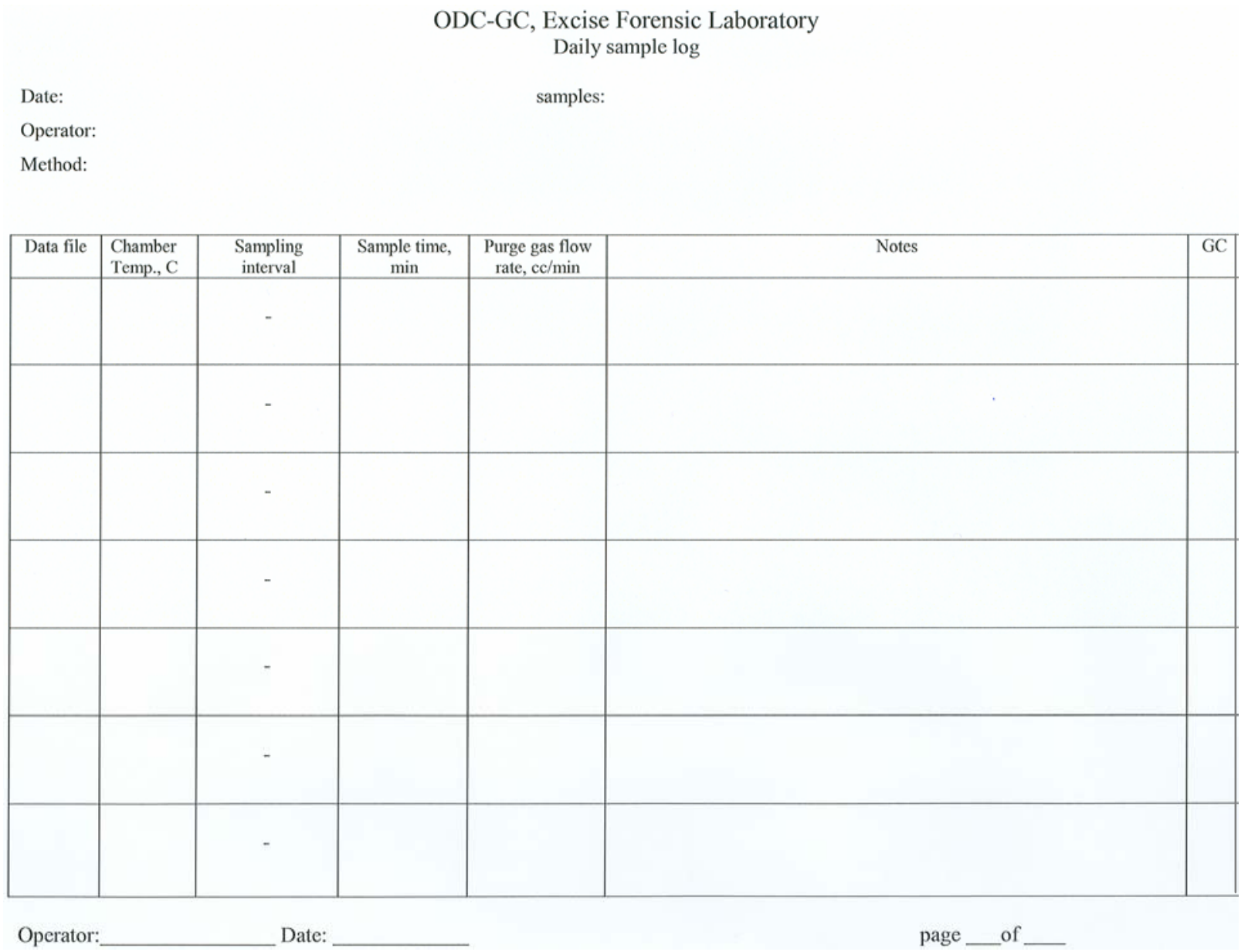

D.1 



\section{Appendix E}

\section{Excel Spreadsheet - Data Form with Functions Displayed}





\section{Appendix E}

\section{Excel Spreadsheet - Data Form with Functions Displayed}

\begin{tabular}{|c|c|c|c|c|}
\hline $\begin{array}{l}\text { Data file Name } \\
\text { Date }\end{array}$ & & & & \\
\hline $\begin{array}{l}\text { data file, } \\
\text { SIG10 }\end{array}$ & 1 & 2 & 3 & 4 \\
\hline Temperature, C & room temperature & room temperature & $40 \mathrm{C}$ & $40 \mathrm{C}$ \\
\hline Analyte & & Peak Area & & \\
\hline CFC-11 & & & & \\
\hline CFC-12 & & & & \\
\hline CFC-13 & & & & \\
\hline CFC-111 & & & & \\
\hline CFC-112 & & & & \\
\hline sym CFC-112 & & & & \\
\hline CFC-113 & & & & \\
\hline CFC-113a & & & & \\
\hline CFC-114 & & & & \\
\hline CFC-115 & & & & \\
\hline CFC-212 & & & & \\
\hline CFC-214cb & & & & \\
\hline CFC-215 & & & & \\
\hline CFC-216 & & & & \\
\hline Halon-1211 & & & & \\
\hline Halon-1301 & & & & \\
\hline Halon-2402 & & & & \\
\hline HCFC141b & & & & \\
\hline HCFC-225ca & & & & \\
\hline HCFC-225cb & & & & \\
\hline HCFC-4310mee & & & & \\
\hline HFE-7100 & & & & \\
\hline HFE-7200 & & & & \\
\hline carbon tetrachloride & & & & \\
\hline methylene chloride & & & & \\
\hline chloroform & & & & \\
\hline methyl chloroform & & & & \\
\hline 1,1,2-trichloroethane & & & & \\
\hline 1,1,2-trichloroethyle & & & & \\
\hline $\begin{array}{l}\text { 1,1,2,2- } \\
\text { tetrachloroethane }\end{array}$ & & & & \\
\hline $\begin{array}{l}1,1,1,2- \\
\text { tetrachlorethane }\end{array}$ & & & & \\
\hline $\begin{array}{l}1,1,2,2- \\
\text { tetrachloroethylene }\end{array}$ & & & & \\
\hline 1,2-dichloroethane & & & & \\
\hline 1,2-dichloroethylene & & & & \\
\hline 1,3-dichloropropene & & & & \\
\hline 2-bromopropane & & & & \\
\hline
\end{tabular}




\begin{tabular}{|c|c|c|c|c|}
\hline Analyte & & Relative Peak Area & & \\
\hline CFC-11 & =B6/(AVERAGE(B6:C6)) & $\begin{array}{l}=\text { C6/(AVERAGE(B6:C6)) } \\
\text { (A) }\end{array}$ & =D6/(AVERAGE(B6:C6)) & =E6/(AVERAGE(B6:C6)) \\
\hline CFC-12 & $=$ =B7/(AVERAGE(B7:C7)) & $=$ C7/(AVERAGE(B7:C7)) & =D7/(AVERAGE(B7:C7)) & $=$ =E7/(AVERAGE(B7:C7)) \\
\hline CFC-13 & =B8/(AVERAGE(B8:C8)) & $=$ C8/(AVERAGE(B8:C8)) & =D8/(AVERAGE(B8:C8)) & =E8/(AVERAGE(B8:C8)) \\
\hline CFC-111 & =B9/(AVERAGE(B9:C9)) & $=$ C9/(AVERAGE(B9:C9)) & =D9/(AVERAGE(B9:C9)) & =E9/(AVERAGE(B9:C9)) \\
\hline CFC-112 & $=$ =B10/(AVERAGE(B10:C10)) & $=\mathrm{C} 10 /(\mathrm{AVERAGE}(\mathrm{B} 10: \mathrm{C} 10))$ & $=$ D10/(AVERAGE(B10:C10)) & $=$ E10/(AVERAGE $(B 10: C 10))$ \\
\hline sym CFC-112 & =B11/(AVERAGE(B11:C11)) & $=$ C11/(AVERAGE $(B 11: C 11))$ & $=$ D11/(AVERAGE(B11:C11)) & $=$ E11/(AVERAGE(B11:C11)) \\
\hline CFC-113 & $=$ =B12/(AVERAGE(B12:C12)) & $=$ C12/(AVERAGE(B12:C12)) & $=$ =12/(AVERAGE(B12:C12)) & $=$ E12/(AVERAGE(B12:C12)) \\
\hline CFC-113a & =B13/(AVERAGE(B13:C13)) & $=$ C13/(AVERAGE $($ B13:C13)) & $=$ =13/(AVERAGE(B13:C13)) & $=$ E13/(AVERAGE(B13:C13)) \\
\hline CFC-114 & =B14/(AVERAGE(B14:C14)) & $=$ C14/(AVERAGE(B14:C14)) & $=$ D14/(AVERAGE(B14:C14)) & $=$ E14/(AVERAGE(B14:C14)) \\
\hline CFC-115 & =B15/(AVERAGE(B15:C15)) & $=$ C15/(AVERAGE(B15:C15)) & $=$ =15/(AVERAGE(B15:C15)) & $=$ E15/(AVERAGE(B15:C15)) \\
\hline CFC-212 & $=$ =B16/(AVERAGE(B16:C16)) & $=$ C16/(AVERAGE $(B 16: C 16))$ & $=$ D16/(AVERAGE(B16:C16)) & $=$ E16/(AVERAGE $(B 16: C 16))$ \\
\hline CFC-214cb & $=$ =B17/(AVERAGE(B17:C17)) & $=$ C17/(AVERAGE(B17:C17)) & $=$ D17/(AVERAGE(B17:C17)) & $=$ E17/(AVERAGE(B17:C17)) \\
\hline CFC-215 & =B18/(AVERAGE(B18:C18)) & $=$ C18/(AVERAGE(B18:C18)) & $=$ =18/(AVERAGE(B18:C18)) & $=$ E18/(AVERAGE(B18:C18)) \\
\hline CFC-216 & =B19/(AVERAGE(B19:C19)) & $=$ C19/(AVERAGE(B19:C19)) & $=$ =19/(AVERAGE(B19:C19)) & $=$ E19/(AVERAGE(B19:C19)) \\
\hline Halon-1211 & $=$ =B20/(AVERAGE(B20:C20)) & $=\mathrm{C} 20 /(\mathrm{AVERAGE}(\mathrm{B} 20: \mathrm{C} 20))$ & $=$ D20/(AVERAGE(B20:C20)) & $=$ E20/(AVERAGE $(B 20: C 20))$ \\
\hline Halon-1301 & =B21/(AVERAGE(B21:C21)) & $=$ C21/(AVERAGE $(B 21: C 21))$ & $=$ D21/(AVERAGE(B21:C21)) & $=$ E21/(AVERAGE(B21:C21)) \\
\hline Halon-2402 & =B22/(AVERAGE(B22:C22)) & $=$ C22/(AVERAGE(B22:C22)) & =D22/(AVERAGE(B22:C22)) & $=$ E22/(AVERAGE(B22:C22)) \\
\hline HCFC141b & =B23/(AVERAGE(B23:C23)) & $=$ C23/(AVERAGE $(B 23: C 23))$ & =D23/(AVERAGE(B23:C23)) & $=$ E23/(AVERAGE(B23:C23)) \\
\hline HCFC-225ca & $=$ =B24/(AVERAGE(B24:C24)) & $=$ C24/(AVERAGE $(B 24: C 24))$ & $=$ D24/(AVERAGE(B24:C24)) & $=$ E24/(AVERAGE(B24:C24)) \\
\hline HCFC-225cb & =B25/(AVERAGE(B25:C25)) & $=$ C25/(AVERAGE(B25:C25)) & $=$ =25/(AVERAGE(B25:C25)) & $=$ E25/(AVERAGE(B25:C25)) \\
\hline HCFC-4310mee & $=$ =B26/(AVERAGE(B26:C26)) & $=$ C26/(AVERAGE(B26:C26)) & $=$ =26/(AVERAGE(B26:C26)) & $=$ E26/(AVERAGE(B26:C26)) \\
\hline HFE-7100 & =B27/(AVERAGE(B27:C27)) & $=$ C27/(AVERAGE(B27:C27)) & =D27/(AVERAGE(B27:C27)) & $=$ E27/(AVERAGE(B27:C27)) \\
\hline HFE-7200 & =B28/(AVERAGE(B28:C28)) & $=$ C28/(AVERAGE(B28:C28)) & $=$ =28/(AVERAGE(B28:C28)) & $=$ E28/(AVERAGE(B28:C28)) \\
\hline $\begin{array}{l}\text { carbon } \\
\text { tetrachloride }\end{array}$ & =B29/(AVERAGE(B29:C29)) & $=$ C29/(AVERAGE(B29:C29)) & =D29/(AVERAGE(B29:C29)) & $=$ E29/(AVERAGE(B29:C29)) \\
\hline $\begin{array}{l}\text { methylene } \\
\text { chloride }\end{array}$ & =B30/(AVERAGE(B30:C30)) & $=\mathrm{C} 30 /(\mathrm{AVERAGE}(\mathrm{B} 30: \mathrm{C} 30))$ & $=$ =30/(AVERAGE(B30:C30)) & $=$ E30/(AVERAGE $(B 30: C 30))$ \\
\hline chloroform & =B31/(AVERAGE(B31:C31)) & $=$ C31/(AVERAGE $(B 31: C 31))$ & =D31/(AVERAGE(B31:C31)) & $=$ E31/(AVERAGE(B31:C31)) \\
\hline $\begin{array}{l}\text { methyl } \\
\text { chloroform }\end{array}$ & =B32/(AVERAGE(B32:C32)) & $=$ C32/(AVERAGE(B32:C32)) & =D32/(AVERAGE(B32:C32)) & $=$ E32/(AVERAGE(B32:C32)) \\
\hline $\begin{array}{l}1,1,2- \\
\text { trichloroethane }\end{array}$ & =B33/(AVERAGE(B33:C33)) & $=$ C33/(AVERAGE(B33:C33)) & =D33/(AVERAGE(B33:C33)) & $=$ E33/(AVERAGE(B33:C33)) \\
\hline $\begin{array}{l}1,1,2- \\
\text { trichloroethylene }\end{array}$ & =B34/(AVERAGE(B34:C34)) & $=\mathrm{C} 34 /(\mathrm{AVERAGE}(\mathrm{B} 34: \mathrm{C} 34))$ & =D34/(AVERAGE(B34:C34)) & $=$ E34/(AVERAGE(B34:C34)) \\
\hline $\begin{array}{l}1,1,2,2- \\
\text { tetrachloroethane }\end{array}$ & =B35/(AVERAGE(B35:C35)) & $=$ C35/(AVERAGE $(B 35: C 35))$ & =D35/(AVERAGE(B35:C35)) & $=$ E35/(AVERAGE(B35:C35)) \\
\hline $\begin{array}{l}1,1,1,2- \\
\text { tetrachlorethane }\end{array}$ & =B36/(AVERAGE(B36:C36)) & $=$ C36/(AVERAGE(B36:C36)) & =D36/(AVERAGE(B36:C36)) & $=$ E36/(AVERAGE(B36:C36)) \\
\hline $\begin{array}{l}1,1,2,2- \\
\text { tetrachloroethyle } \\
\text { ne } \\
\end{array}$ & =B37/(AVERAGE(B37:C37)) & $=$ C37/(AVERAGE(B37:C37)) & =D37/(AVERAGE(B37:C37)) & $=$ E37/(AVERAGE(B37:C37)) \\
\hline $\begin{array}{l}1,2- \\
\text { dichloroethane }\end{array}$ & =B38/(AVERAGE(B38:C38)) & $=$ C38/(AVERAGE(B38:C38)) & =D38/(AVERAGE(B38:C38)) & $=$ E38/(AVERAGE(B38:C38)) \\
\hline $\begin{array}{l}, 2- \\
\text { dichloroethylene }\end{array}$ & =B39/(AVERAGE(B39:C39)) & $=$ C39/(AVERAGE(B39:C39)) & =D39/(AVERAGE(B39:C39)) & $=$ E39/(AVERAGE(B39:C39)) \\
\hline $\begin{array}{l}1,3- \\
\text { dichloropropene }\end{array}$ & $=$ B40/(AVERAGE(B40:C40)) & $=$ C40/(AVERAGE $(B 40: C 40))$ & $=$ D40/(AVERAGE $(B 40: C 40))$ & $=\mathrm{E} 40 /(\mathrm{AVERAGE}(\mathrm{B} 40: \mathrm{C} 40))$ \\
\hline 2-bromopropane & $=$ =B41/(AVERAGE(B41:C41)) & $=$ C41/(AVERAGE(B41:C41)) & $=$ D41/(AVERAGE(B41:C41)) & $=$ E41/(AVERAGE(B41:C41)) \\
\hline
\end{tabular}

